\title{
A genetically encoded red fluorescence dopamine biosensor enables dual imaging of dopamine and norepinephrine
}

Chihiro Nakamoto ${ }^{\mathrm{a}, \mathrm{b}, 1}$, Yuhei Goto ${ }^{\mathrm{c}, \mathrm{d}, \mathrm{e}, 1}$, Yoko Tomizawa ${ }^{\mathrm{c}, \mathrm{d}}$, Yuko Fukata ${ }^{\mathrm{f}, \mathrm{g}}$, Masaki Fukata ${ }^{\mathrm{f}, \mathrm{g}}$, Kasper

Harpsøe $^{\text {h }}$ David E. Gloriam ${ }^{\text {h }}$ Kazuhiro Aoki, ${ }^{\text {c,de, }, 2}$ and Tomonori Takeuchi a,b,2

aDepartment of Biomedicine, Aarhus University, Hoegh-Guldbergsgade 10, DK8000, Aarhus C, Denmark

bDanish Research Institute of Translational Neuroscience - DANDRITE, Nordic-EMBL Partnership for Molecular Medicine, Aarhus University, Hoegh-Guldbergsgade 10, DK8000, Aarhus C, Denmark

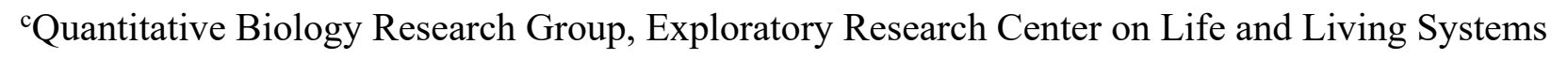
(ExCELLS), National Institutes of Natural Sciences, 5-1 Higashiyama, Myodaiji-cho, Okazaki, Aichi 444-8787, Japan

${ }^{\mathrm{d} D i v i s i o n}$ of Quantitative Biology, National Institute for Basic Biology, National Institutes of Natural Sciences, 5-1 Higashiyama, Myodaiji-cho, Okazaki, Aichi 444-8787, Japan

eDepartment of Basic Biology, School of Life Science, SOKENDAI (The Graduate University for Advanced Studies), 5-1 Higashiyama, Myodaiji-cho, Okazaki, Aichi 444-8787, Japan

fDivision of Membrane Physiology, Department of Molecular and Cellular Physiology, National Institute for Physiological Sciences, National Institutes of Natural Sciences, 5-1 Higashiyama, Myodaiji-cho, Okazaki, Aichi 444-8787, Japan

gDepartment of Physiological Sciences, School of Life Science, SOKENDAI (The Graduate University for Advanced Studies), 5-1 Higashiyama, Myodaiji-cho, Okazaki, Aichi 444-8787, Japan hDepartment of Drug Design and Pharmacology, University of Copenhagen, Universitetsparken 2 , 2100 Copenhagen, Denmark 
$27{ }^{1}$ These authors equally contributed to this work.

28 2To whom correspondence may be addressed: Kazuhiro Aoki (k-aoki@nibb.ac.jp) and Tomonori

29 Takeuchi (tomonori.takeuchi@,biomed.au.dk).

\section{Author ORCIDs}

32 Chihiro Nakamoto: https://orcid.org/0000-0002-5685-8773

33 Yuhei Goto: https://orcid.org/0000-0002-5597-158X

34 Yuko Fukata: https://orcid.org/0000-0001-7724-8643

35 Masaki Fukata: https://orcid.org/0000-0001-5200-9806

36 Kasper Harpsøe: https://orcid.org/0000-0002-9326-9644

37 David E. Gloriam: https://orcid.org/0000-0002-4299-7561

38 Kazuhiro Aoki: https://orcid.org/0000-0001-7263-1555

39 Tomonori Takeuchi: https://orcid.org/0000-0002-9981-4260

\section{$41 \quad$ Classification}

42 Major classification: Biological Sciences

43 Minor classification: Cell Biology

\section{Keywords}

46 GPCR | dopamine | norepinephrine | fluorescence probe | hippocampal neuron

\section{Author contributions}

49 Y.G., K.A. and T.T. designed research; C.N., Y.G., Y.T. and K.A. performed experiments; Y.F. and M.F. 50 supervised and prepared primary hippocampal neuron experiments; K.H. and D.E.G. performed in silico 
bioRxiv preprint doi: https://doi.org/10.1101/2020.05.25.115162; this version posted May 26, 2020. The copyright holder for this preprint (which

was not certified by peer review) is the author/funder, who has granted bioRxiv a license to display the preprint in perpetuity. It is made available under aCC-BY-NC-ND 4.0 International license.

51 structural analysis and suggested mutations; C.N., Y.G., and Y.T. analyzed the data; C.N., Y.G., K.A. 52 and T.T. wrote the manuscript.

53

54 The authors declare no competing interest.

55

\section{This PDF file includes:}

57 Main Test

58 Figures 1 to 5 


\section{Abstract}

Dopamine (DA) and norepinephrine (NE) are pivotal neuromodulators that regulate a broad range of

61 brain functions, often in concert. Despite their physiological importance, untangling the relationship between DA and NE in finely controlling output functions is currently challenging, primarily due to a lack of techniques to visualize spatiotemporal dynamics with sufficiently high selectivity. Although genetically encoded fluorescent biosensors have been developed to detect DA, their poor selectivity prevents distinguishing DA from NE. Here, we report the development of a red fluorescent genetically encoded GPCR (G protein-coupled receptor)-activation reporter for DA termed 'R-GenGAR-DA'. More specifically, a circular permutated red fluorescent protein (cpmApple) was inserted into the third intracellular loop of human DA receptor D1 (DRD1) followed by the screening of mutants within the linkers between DRD1 and cpmApple. We developed two variants: R-GenGAR-DA1.1, which brightened following DA stimulation, and R-GenGAR-DA1.2, which dimmed. R-GenGAR-DA1.2 demonstrated reasonable dynamic range $\left(\Delta \mathrm{F} / \mathrm{F}_{0}=-50 \%\right)$ and $\mathrm{DA}$ affinity $\left(\mathrm{EC}_{50}=0.7 \mu \mathrm{M}\right)$ as well as the highest selectivity for DA over NE (143-fold) amongst available DA biosensors. Due to its high selectivity, R-GenGAR-DA1.2 allowed dual-color fluorescence live imaging for monitoring DA and NE, combined with the existing green-NE biosensor GRABNE1m, which has high selectivity for NE over DA (>350-fold) in HeLa cells and hippocampal neurons grown from primary culture. By enabling precise measurement of DA, as well as simultaneous visualization of DA and NE, the red-DA biosensor Rorganizing key brain functions. 


\section{Significance Statement}

80 The neuromodulators dopamine and norepinephrine modulate a broad range of brain functions, often in

81 concert. One current challenge is to measure dopamine and norepinephrine dynamics simultaneously

82 with high spatial and temporal resolution. We therefore developed a red-dopamine biosensor that has

83 143-fold higher selectivity for dopamine over norepinephrine. Taking advantage of its high selectivity

84 for dopamine over norepinephrine, this red-dopamine biosensor allowed dual-color fluorescence live

85 imaging for monitoring dopamine and norepinephrine in both HeLa cells and hippocampal neurons in

86 vitro combined with the existing green-norepinephrine biosensor that has 350 -fold selectivity for

87 norepinephrine over dopamine. Thus, this approach can provide new opportunities to advance our

88 understanding of high spatial and temporal dynamics of dopamine and norepinephrine in normal and

89 abnormal brain functions. 


\section{Introduction}

91 The catecholaminergic neuromodulators dopamine (DA) and norepinephrine (NE) have very high

92 structural similarity, differing only by a single hydroxy group. Dopaminergic projections mainly

93 originate from the ventral tegmental area and substantia nigra pars compacta (1), whilst noradrenergic

94 projections originate from the locus coeruleus (LC) $(2,3)$. It was discovered recently that noradrenergic

95 LC axons co-released DA along with NE (4-6). DA is involved in reward (7, 8), motivation (9), novelty

96 response $(10)$, and motor control $(11,12)$. In addition, the involvement of DA and NA in many brain

97 functions overlaps $(13,14)$, such as learning and memory $(10,15)$, arousal $(16,17)$, and stress response

$98(6,18)$. In particular, the prefrontal cortex receives both dopaminergic and noradrenergic projections,

99 and these systems are involved in attention $(19,20)$ and working memory (21-23). Furthermore,

100 dysfunction of dopaminergic or noradrenergic systems are thought to be associated with psychiatric

101 disorders and neurodegenerative diseases, such as attention-deficit/hyperactivity disorder (ADHD),

102 schizophrenia, and Parkinson's disease (24-26).

103

Although interactions between dopamine and norepinephrine theoretically depend on the timing of

release, spatial diffusions, concentrations, and neuromodulator ratios, little is actually known about these

properties with high spatial and temporal resolution within the same preparation due to the technical limitations. For example, microdialysis with high-performance liquid chromatography has high sensitivity and selectivity to detect either DA and NE, but suffers from poor spatial and temporal resolution $(27,28)$. In contrast, fast-scan cyclic voltammetry (29) and a synthetic catecholamine nanosensor (30) have higher sensitivity and temporal resolution, but cannot distinguish between DA and

NE. A method combining sensitivity, specificity, and spatiotemporal resolution is required to

111 satisfactorily answer research questions regarding timing of release, spatial diffusions, concentrations, and ratios. 
115 imaging (31-34). Binding of DA or NE to the sensor induces a conformational change, which couples

116 with a change in the fluorescence of circular-permutated fluorescent protein, such as green fluorescent

117 protein (GFP) for green fluorescence (31-34) and mApple for red fluorescence (34). The green-NE

118 biosensor, GRAB ${ }_{\mathrm{NE} 1 \mathrm{~m}}$ (abbreviated NE1m), has a high selectivity for $\mathrm{NE}(>350$-fold selectivity for NE

119 over DA) (33). However, current DA biosensors do not have high enough selectivity for DA over NE

120 [Green-DA biosensors: dLight1.1 (60-fold, but see SI Appendix, Fig. S7), GRAB ${ }_{\text {DA1h }}(\sim$ 10-fold), and

$121 \operatorname{GRAB}_{\mathrm{DA} 2 \mathrm{~m}}\left(15\right.$-fold); Red-DA biosensor: $\operatorname{rGRAB}_{\mathrm{DA} 1 \mathrm{~m}}(22$-fold)] $(31,32,34)$ and consequently, it is

122 difficult to use these DA biosensors for the simultaneous detection of DA and NE.

123 To image DA and NE dynamics simultaneously with high spatial and temporal resolution, we

124 developed a red-DA biosensor using circular-permutated mApple (cpmApple), which has high selectivity

125 for DA (143-fold selectivity for DA over NE). Using this red-DA biosensor with the existing green-NE

126 biosensor, NE1m, which has high selectivity for NE (33), allowed us to successfully perform dual-color

127 fluorescence monitoring of DA and NE with live imaging in both HeLa cells and primary culture of rat

128 hippocampal neurons in vitro. 


\section{Results}

130 Development and characterization of a red-DA biosensor. To develop a genetically encoded red

131 fluorescence DA biosensor, we adopted the same approach as used to develop the green-DA sensors

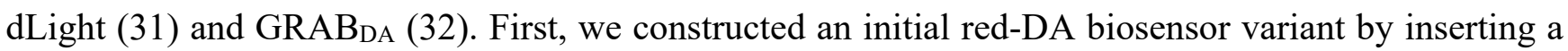
red fluorescent protein, cpmApple (35), with linker sequences between Lys 232 and Lys 269 of human DA receptor D1 (DRD1), similarly to that done to construct dLight. We named it red fluorescent genetically encoded GPCR activation reporter for DA, 'R-GenGAR-DA1.0' (abbreviated DA1.0; Fig. 1A). However, when DA was applied, DA1.0 did not exhibit a fluorescence response (SI Appendix, Fig. $\mathrm{S} 1 A$ ). To improve its fluorescence response to DA, random mutagenesis was performed on the linker peptide sequences between DRD1 and cpmApple on DA1.0 (Fig. 1A). HeLa cells expressing mutants of DA1.0 were stimulated by application of DA, and the change in red fluorescence intensity was quantified (Fig. 1B). Of 864 mutants, we selected three mutants (\#76, \#310, and \#430) that responded positively to mutants showed detectable red fluorescence increases in response to DA application and this response was blocked by the DRD1/5 antagonist SCH 23390 (SCH) (Fig. $1 C$ and D, and SI Appendix, Fig. S1B).

144 The amino acid sequences of mutated linkers were determined in these mutants (SI Appendix, Fig. S1C). We selected \#76 ('R-GenGAR-DA1.1', abbreviated DA1.1) because it showed the largest positive response to DA amongst the three mutants. We then characterized the dose-response curves of DA1.1

147 for $\mathrm{DA}$ and $\mathrm{NE}$ and calculated the half maximal effective concentration $\left(\mathrm{EC}_{50}\right)$. As a result, $\mathrm{DA} 1.1$ showed 12.6-fold selectivity for DA over NE (Fig. 1E).

Development and characterization of an inverse-type red-DA biosensor. The dynamic range of to make further improvements. We attempted to expand the dynamic range of DA1.1 by introducing the 
154 mutation of dLight1.2; SI Appendix, Fig. S2A), and addition of Glu to the N-terminal linker (dLight1.3a;

155 Fig. 2A) were previously shown to significantly increase the dynamic range of dLight1.1 (31). The

156 F129A mutation in DA1.1, however, led to only a slight increase in the fluorescent signal upon DA

157 application (SI Appendix, Fig. S2B) and its sensitivity to both DA and NE was lower than that of the

158 original DA1.1 (data not shown). Surprisingly, the addition of Glu to the N-terminal linker in DA1.1

159 showed bright red fluorescence in the basal state. This variant had substantially reduced fluorescence

160 signal in response to DA, which subsequently returned to basal level following treatment with SCH (Fig.

$1612 B$ ). We named this inverse type red fluorescence DA biosensor 'R-GenGAR-DA1.2' (abbreviated

162 DA1.2).

Unexpectedly, time-lapse imaging of DA1.2 in HeLa cells showed that the baseline fluorescent

164 signals increased gradually in both vehicle and control conditions (data not shown). We explored the

165 cause of this phenomenon and found that the DA1.2 baseline fluorescent signals were seemingly associated with thermochromism and photochromism stemming from cpmApple (36) (SI Appendix, Fig.

167 S3). The former effect, thermochromism, was apparent from the inverse relationship between baseline 168 fluorescent signals of R-GenGAR-DA and incubation temperature (SI Appendix, Fig. S3 A-D).

169 Thermochromism was observed when test compounds were added to our experimental system. Therefore, 170 imaging was performed after temperature equilibration (SI Appendix, Fig. S4 and Fig. S5). With respect 171 to photochromism, irradiating light at wavelengths of either $488 \mathrm{~nm}$ or $561 \mathrm{~nm}$ induced an increase in 172 basal red fluorescence of DA1.2 expressed in HeLa cells under constant medium temperature (SI 173 Appendix, Fig. S3E). This effect was most pronounced when the irradiation light was at full power.

174 Because light of $488 \mathrm{~nm}$ and $561 \mathrm{~nm}$ is generally used to excite green and red fluorophores respectively, 175 it was problematic that the photochromism on DA1.2 was induced by the irradiation of those light 176 wavelengths, especially when we combined DA1.2 with another fluorescent biosensor to perform dual177 color time-lapse imaging in HeLa cells and primary hippocampal neurons (Fig. 3 and Fig. 5). We found 
bioRxiv preprint doi: https://doi.org/10.1101/2020.05.25.115162; this version posted May 26, 2020. The copyright holder for this preprint (which was not certified by peer review) is the author/funder, who has granted bioRxiv a license to display the preprint in perpetuity. It is made available under aCC-BY-NC-ND 4.0 International license.

following irradiation of two streams of light (561 nm followed by $488 \mathrm{~nm}$ ) for $150 \mathrm{~s}$ (SI Appendix, Fig. $\mathrm{S} 3 F)$. Therefore, pre-light exposure just prior to dual-color time-lapse imaging was conducted to reduce the photochromism effect in DA1.2 (Fig. 3 and Fig. 5, SI Appendix, Fig. S5D and Table S1). Time-lapse imaging of DA1.2 with temperature equilibration (SI Appendix, Fig. S5B) showed that DA application lowered red fluorescence, which was restored following SCH treatment (Fig. 2C). Baseline fluorescence intensity still increased moderately in both vehicle and control conditions, possibly due to photochromism. The dose-response curve with temperature equilibration (SI Appendix, Fig. S4D-F) shows that DA1.2 has a slightly higher dynamic range and comparable affinity to DA ( $\max \Delta \mathrm{F} / \mathrm{F}_{0}=-$ $0.40 \pm 0.01 \%$ and $\mathrm{EC}_{50}=0.68 \pm 0.08 \mu \mathrm{M}$ ) compared to that of DA1.1 (Fig. $2 D$ ). It is of note that the selectivity of DA1.2 for DA over NE was 143-fold, much higher than that of DA1.1 (Fig. 2D), which was due to the decrease in the affinity of DA1.2 to NE. In order to further enhance the selectivity of DA1.2 for DA over NE, we attempted to predict mutations based on ligand-receptor structure models (see SI Appendix, Materials and Methods). Since the difference between DA and NE is only one additional hydroxy group on NE, preference for DA might be accomplished by making the area around the binding site unfavorable for this hydroxy group. Based on a structural model complex of the DRD1 with either DA or NE in the binding site (SI Appendix, Fig. S6A), we then introduced 13 mutations to DA1.2 designed to increase preference for DA over NE (SI Appendix, Fig. S6B). Six of the 13 mutants showed a change in red fluorescence response to DA (SI Appendix, Fig. S6 C and D). Although the doseresponse curves with temperature equilibration for both DA and NE were obtained from three mutants, none of these demonstrated an increase in selectivity for DA over NE compared to that of DA1.2 (SI Appendix, Fig. S6E). We then confirmed that the selectivity of the red-DA biosensor DA1.2 (143-fold) was higher than that of green-DA biosensors dLight1.1 (17-fold), dLight1.2 (32-fold), and dLight1.3a (19-fold) in our experimental conditions (SI Appendix, Fig. S7). Consequently, 143-fold selectivity for DA over NE in DA1.2 is the highest amongst currently available DA biosensors $(31,34)$. 
We further characterized how DA1.2 responded to a variety of test compounds. The DRD1/5

agonist SKF 81297 led to a partial response from DA1.2, whilst the response to DA was blocked by the

DRD1/5 antagonist SCH (Fig. 2E). The application of several other neurotransmitters/neuromodulators

showed no significant response in DA1.2 (Fig. 2E). In addition, we confirmed that DA1.2 induced no

cyclic adenosine monophosphate (cAMP) increase upon DA application, indicating that, unlike wild-

type DRD1, DA1.2 activity does not activate the canonical Gas signaling pathway (SI Appendix, Fig.

S8).

Dual-color fluorescence imaging of DA and NE in HeLa cells. We then tested the simultaneous imaging of DA and NE at the single-cell level. To accomplish this, both DA1.2 and a green-NE sensor,

NE1m, which has high selectivity for NE over DA ( $>350$-fold) (33), were co-expressed in HeLa cells

(Fig. 3A). Following irradiation of DA1.2 by two streams of light (561 nm followed by $488 \mathrm{~nm}$ ) to reduce

SI Appendix, Fig. S5D). As we expected, DA1.2 exhibited a decrease in fluorescence to DA, but not to

and $B$ ), confirming that the decrease in fluorescence could indeed be attributed to DA binding to DA1.2.

Meanwhile, NE1m showed an increase in green fluorescence upon application of NE, but not DA, and existing green-NE biosensor NE1m can distinguish DA and NE, respectively, in HeLa cells.

Dual-color fluorescence imaging of DA and NE in a primary culture of rat hippocampal neurons.

To further test the application of DA1.2, we introduced DA1.2 into rat primary hippocampal neurons, 
228 Application of DA $(5 \mu \mathrm{M})$ led to reduced DA1.2 red fluorescence, and this was restored to baseline by $229 \mathrm{SCH}$ treatment $(5 \mu \mathrm{M})($ Fig. $4 A$ and $B)$. Conversely, pretreatment with SCH completely suppressed the 230 response of DA1.2 to DA (Fig. 4C), indicating that DA1.2 was successful in facilitating the visualization 231 of DA in primary hippocampal neurons. The dose-response curve for DA with temperature equilibration 232 was obtained in primary hippocampal neurons expressing DA1.2. In this set up, DA1.2 showed max $233 \Delta \mathrm{F} / \mathrm{F}_{0}=-0.51 \pm 0.05 \%$, and an $\mathrm{EC}_{50}$ value of $0.56 \pm 0.01 \mu \mathrm{M}$ (Fig. $4 D$ ), which were comparable to the 234 results in HeLa cells.

235 We finally performed dual-color fluorescence imaging of DA and NE in the primary culture of rat 236 hippocampal neurons. DA1.2 and NE1m were co-expressed in the primary hippocampal neurons (Fig. $2375 A$ ). After the effects of photochromism were reduced using two streams of light (561 nm followed by $238488 \mathrm{~nm})$, we then applied compounds in the following order: NE $(1 \mu \mathrm{M}), \mathrm{DA}(5 \mu \mathrm{M})$ followed by YO $239(1 \mu \mathrm{M})$, and SCH $(5 \mu \mathrm{M})($ SI Appendix, Fig. S5D). As we observed in HeLa cells, DA, but not NE 240 application, led to a decrease in the red fluorescence signal of DA1.2, which was restored following SCH 241 treatment (Fig. $5 B$ and $C$ and SI Appendix, Fig. S9 $C$ and D). In addition, we observed a NE-induced 242 increase in NE1m green fluorescence, and this fluorescence response was blocked by YO treatment (Fig. $2435 B$ and $C$ and SI Appendix, Fig. S9 $C$ and $D)$.

\section{Discussion}

247 We have developed genetically encoded red fluorescent DA sensors R-GenGAR-DA1.1 and DA1.2, 248 which respond positively and negatively to DA, respectively. Specifically, DA1.2 demonstrated 249 reasonable dynamic range $\left(\Delta \mathrm{F} / \mathrm{F}_{0}=-50 \%\right)$ and DA affinity $\left(\mathrm{EC}_{50}=0.7 \mu \mathrm{M}\right)$ as well as high selectivity 250 for DA (143-fold higher affinity than for NE). In HeLa cells, dual-color live imaging of DA and NE was 251 successfully performed using DA1.2 combined with the existing green-NE biosensor NE1m, which has 252 high selectivity for NE over DA (> 350-fold) (33). Furthermore, DA1.2 and NE1m were also co- 
expressed in the primary culture of rat hippocampal neurons, allowing dual-color live imaging of DA and NE in vitro. We thus successfully demonstrated that application of two different color-based fluorescent neurochemical sensors (i.e. cpGFP- and cpmApple-based sensors) with high selectivity for each ligand allow us to monitor two different neurochemicals simultaneously.

A striking feature of DA1.2 is its high selectivity for DA over NE. For a DA biosensor, selectivity for DA over NE is critical to avoid cross-reactivity for imaging in the brain areas where NE is present at relatively higher amount than DA $(5,28,37,38)$. In our experimental conditions, the specificity for DA over NE, shown by green-DA biosensor dLight1 variants, was lower than that in a previous study (31): dLight1.1 (17-fold), dLight1.2 (32-fold), dLight1.3a (19-fold) (SI Appendix, Fig. S7). Sun and colleagues reported that DA biosensors GRAB $\mathrm{DA}_{\mathrm{DA}}$ also did not have enough selectivity for DA over NE: GRAB $\mathrm{DA}_{\mathrm{h}}$ ( 10-fold), GRAB DA2m $_{\text {(15-fold), and rGRAB }}$ DA1m $(22$-fold) $(32,34)$. Thus, DA1.2 has the highest selectivity for DA over NE (143-fold) compared to all other currently available DA biosensors. Although we tried to further increase the selectivity of DA1.2 by introducing mutations predicted from in silico models (SI Appendix, Fig. S6), the selectivity of DA1.2 was not raised above the already obtained 143fold level, possibly due to the use of models in the absence of the crystal structure of DRD1. Taking advantage of this high selectivity of DA1.2 for DA over NE, we succeeded in detecting DA and NE simultaneously in HeLa cells and primary hippocampal neurons in vitro by dual-color imaging combined with the existing green-NE biosensor NE1m, which has the highest selectivity for NE over DA (33). The affinity of DA1.2 to $\mathrm{DA}\left(\mathrm{EC}_{50}=0.68 \mu \mathrm{M}\right.$ in HeLa cells, and $\mathrm{EC}_{50}=0.56 \mu \mathrm{M}$ in primary hippocampal neurons) was at sub-micromolar levels, which is within the range of available DA biosensors, comparable

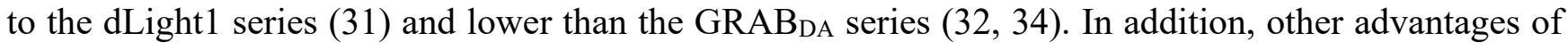
the red fluorescent DA1.2 sensor are lower phototoxicity and higher tissue penetration because of its 275 longer excitation wavelength. Furthermore, DA1.2 enables multiplex imaging with other colored 276 biosensors for different neurochemicals (39, 40), optogenetic actuators (41), intracellular signaling 277 biosensors $(42,43)$, calcium indicators $(44,45)$, and voltage indicators $(46)$. 
vitro, further improvements to DA1.2 will be required for use in in vivo imaging. The main areas in which improvement are required are: [i] expanding the dynamic range and [ii] lowering thermochromism and photochromism. The first concern is the relatively low dynamic range DA1.2 $\left(\Delta \mathrm{F} / \mathrm{F}_{0} \sim-50 \%\right)$. Recent literature on biosensor development has shown that an increase in dynamic range can be achieved by optimization of the linker insertion site, linker length, and, by random mutagenesis, the amino acid sequences on the linkers and the circular-permutated fluorescent protein $(34,47,48)$. In order to expand the dynamic range of DA1.2, these strategies should be applied to DA1.2 in future work. The second concern regarding DA1.2 is thermochromism and photochromism, which is due to cpmApple (36). The thermochromic effect could potentially be avoided if the temperature of the animal is kept constant during in vivo imaging. In addition, it was recently reported that photochromism due to a cpmApple was successfully diminished by introduction of 22 mutations in the cpmApple region of red-dopamine sensor rGRAB $_{\mathrm{DA}}(34)$. Therefore, it may be possible to minimize photochromism in DA1.2 by introducing these mutations into cpmApple. Once those issues are overcome, an improved DA1.2 could be an extremely useful tool for simultaneous measurements of extracellular DA and NE dynamics in the brains of freely moving animals.

Recently, there has been an increased demand for the development of tools to observe DA and NE dynamics simultaneously with high spatial and temporal resolution in vivo. For example, it was reported that pharmacological blockade of dopamine $\mathrm{D}_{1} / \mathrm{D}_{5}$ receptors in the hippocampus prevented a memoryboosting effect induced by environmental novelty or by optogenetic activation of noradrenergic LC neurons in mice (4). Later, Kempadoo and colleagues directly detected co-release of DA along with NE after optogenetic stimulation of LC axons in the hippocampus ex vivo using high-performance liquid chromatography (5). These discoveries raise many questions regarding the co-release of DA and NE 301 from LC terminals into the hippocampus in freely moving animals. For instance, what are the ranges of 302 spatial diffusion and the precise time courses of concentration change? High spatial and temporal dual- 
303 color imaging of DA and NE dynamics in the hippocampus could give us an opportunity to answer these

304 questions. Furthermore, when fiber photometry or two-photon microscopy is applied, the dual-color 305 imaging will enable the measurement of DA and NE at the same spot in the brain. Because of this, the 306 extracellular spatiotemporal dynamics of DA and NE will be comparable to each other under the same 307 conditions.

308 To the best of our knowledge, this is the first time that simultaneous live imaging of extracellular 309 DA and NE has been performed with dual-color fluorescence in both HeLa cells and in a primary culture 310 of rat hippocampal neurons in vitro. Here, this was accomplished using our red-DA biosensor DA1.2 311 combined with the existing green-NE biosensor NE1m. This approach will be able to provide new 312 insights into the high spatial and temporal dynamics of neuromodulators DA and NE in brain areas of 313 interests, leading to advances in our understanding of the mechanisms of interplay between DA and NE 314 in organizing key brain functions. A better understanding of these neuromodulatory systems would have 315 the potential to facilitate new ways of treating psychiatric disorders and neurodegenerative diseases.

\section{Materials and Methods}

319 Animal experiments were approved by the Animal Care Committee of the National Institutes of Natural 320 Sciences in Japan (19A029) and were performed in accordance with its guidelines. Details on animals, 321 and procedures regarding drugs, molecular cloning, saturation polymerase chain reaction (PCR) for the 322 screening of optimal linker sequences, design of DRD1 mutations, cell culture, drug administrations, 323 fluorescence imaging, detection of cAMP signaling using cAMP biosensor, quantification of imaging 324 and data analysis, and statistical analysis are detailed in SI Appendix, Materials and Methods. 
327 ACKNOWLEDGMENTS. We thank all members of the Aoki and Takeuchi laboratories for 328 helpful discussions and assistance. Sachiko Furukawa and Yuri Miyazaki helped with the primary culture 329 of rat hippocampal neurons. The plasmid DNA of GRAB ${ }_{\mathrm{NE} 1 \mathrm{~m}}, \mathrm{RGECO1}$, and DRD1-Tango was 330 provided by Yulong Li, Takeharu Nagai, and Bryan Roth, respectively. We also thank Takanari Inoue, 331 Adrian Duszkiewicz, David Bett, Mai Iwasaki, Yulong Li, Steffen Sinning, and Lina Bukowski for 332 scientific discussion.

333 This work was supported by Japan Society for the Promotion of Science (JSPS) KAKENHI Grants 334 (no.19K16050 to Y.G.; no. 19H03331 to Y.F.; no. 18H04873 to M.F.); Lundbeckfonden (R163-2013335 16327) and Danmarks Frie Forskningsfond | Natural Sciences (8021-00173B) (to D.E.G.); Core Research 336 for Evolutional Science and Technology | Japan Society for the Promotion of Science (JPMJCR1654), 337 JSPS KAKENHI Grants (no. 16KT0069, 16H01425 "Resonance Bio”, 18H04754 “Resonance Bio", 338 18H02444, and 19H05798), and ONO Medical Research Foundation (to K.A.); Novo Nordisk Fonden 339 Young Investigator Award 2017 (NNF17OC0026774), Aarhus Institute of Advanced Studies (AIAS)340 EU FP7 Cofund programme (754513), Lundbeckfonden (DANDRITE-R248-2016-2518), and the 341 Cooperative Study Program (20-105) of National Institute for Physiological Sciences (to T.T.). 


\section{References}

343 1. J. F. Poulin et al., Mapping projections of molecularly defined dopamine neuron subtypes using 344 intersectional genetic approaches. Nat Neurosci 21, 1260-1271 (2018).

345 2. S. D. Robertson, N. W. Plummer, J. de Marchena, P. Jensen, Developmental origins of central 346 norepinephrine neuron diversity. Nat Neurosci 16, 1016-1023 (2013).

347 3. L. A. Schwarz et al., Viral-genetic tracing of the input-output organization of a central noradrenaline 348 circuit. Nature 524, 88-92 (2015).

349 4. T. Takeuchi et al., Locus coeruleus and dopaminergic consolidation of everyday memory. Nature $350 \quad 537,357-362(2016)$.

5. K. A. Kempadoo, E. V. Mosharov, S. J. Choi, D. Sulzer, E. R. Kandel, Dopamine release from the locus coeruleus to the dorsal hippocampus promotes spatial learning and memory. Proc Natl Acad Sci U S A 113, 14835-14840 (2016).

6. B. S. Beas et al., The locus coeruleus drives disinhibition in the midline thalamus via a dopaminergic mechanism. Nat Neurosci 21, 963-973 (2018).

7. W. Schultz, P. Dayan, P. R. Montague, A neural substrate of prediction and reward. Science 275, 1593-1599 (1997).

8. E. E. Steinberg et al., A causal link between prediction errors, dopamine neurons and learning. Nat Neurosci 16, 966-973 (2013).

9. A. A. Hamid et al., Mesolimbic dopamine signals the value of work. Nat Neurosci 19, 117-126 (2016).

10. A. J. Duszkiewicz, C. G. McNamara, T. Takeuchi, L. Genzel, Novelty and dopaminergic modulation of memory persistence: A tale of two systems. Trends Neurosci 42, 102-114 (2019).

11. B. Panigrahi et al., Dopamine is required for the neural representation and control of movement vigor. Cell 162, 1418-1430 (2015).

12. M. W. Howe, D. A. Dombeck, Rapid signalling in distinct dopaminergic axons during locomotion and reward. Nature 535, 505-510 (2016).

13. B. Xing, Y. C. Li, W. J. Gao, Norepinephrine versus dopamine and their interaction in modulating synaptic function in the prefrontal cortex. Brain Res 1641, 217-233 (2016). 
15. S. J. Sara, The locus coeruleus and noradrenergic modulation of cognition. Nat Rev Neurosci 10, 211-223 (2009).

16. M. E. Carter et al., Tuning arousal with optogenetic modulation of locus coeruleus neurons. Nat Neurosci 13, 1526-1533 (2010).

17. A. Eban-Rothschild, G. Rothschild, W. J. Giardino, J. R. Jones, L. de Lecea, VTA dopaminergic neurons regulate ethologically relevant sleep-wake behaviors. Nat Neurosci 19, 1356-1366 (2016).

18. E. Isingrini et al., Resilience to chronic stress is mediated by noradrenergic regulation of dopamine neurons. Nat Neurosci 19, 560-563 (2016).

19. S. Granon et al., Enhanced and impaired attentional performance after infusion of D1 dopaminergic receptor agents into rat prefrontal cortex. J Neurosci 20, 1208-1215 (2000).

20. M. D. Lapiz, D. A. Morilak, Noradrenergic modulation of cognitive function in rat medial prefrontal cortex as measured by attentional set shifting capability. Neuroscience 137, 1039-1049 (2006).

21. M. Wang, S. Vijayraghavan, P. S. Goldman-Rakic, Selective D2 receptor actions on the functional circuitry of working memory. Science 303, 853-856 (2004).

22. S. Vijayraghavan, M. Wang, S. G. Birnbaum, G. V. Williams, A. F. Arnsten, Inverted-U dopamine D1 receptor actions on prefrontal neurons engaged in working memory. Nat Neurosci 10, 376-384 (2007).

23. M. Wang et al., $\alpha 2 \mathrm{~A}$-adrenoceptors strengthen working memory networks by inhibiting cAMP-HCN channel signaling in prefrontal cortex. Cell 129, 397-410 (2007).

24. A. F. Arnsten, S. R. Pliszka, Catecholamine influences on prefrontal cortical function: relevance to treatment of attention deficit/hyperactivity disorder and related disorders. Pharmacol Biochem Behav 99, 211-216 (2011).

25. J. M. Beaulieu, R. R. Gainetdinov, The physiology, signaling, and pharmacology of dopamine receptors. Pharmacol Rev 63, 182-217 (2011).

26. O. Borodovitsyna, M. Flamini, D. Chandler, Noradrenergic modulation of cognition in health and disease. Neural Plast 2017, 6031478 (2017).

27. P. Devoto, G. Flore, P. Saba, M. Fa, G. L. Gessa, Stimulation of the locus coeruleus elicits noradrenaline and dopamine release in the medial prefrontal and parietal cortex. $J$ Neurochem $\mathbf{9 2}$, 368-374 (2005). 
28. J. Van Schoors et al., An improved microbore UHPLC method with electrochemical detection for the simultaneous determination of low monoamine levels in in vivo brain microdialysis samples. $J$ Pharm Biomed Anal 127, 136-146 (2016).

29. D. L. Robinson, B. J. Venton, M. L. Heien, R. M. Wightman, Detecting subsecond dopamine release with fast-scan cyclic voltammetry in vivo. Clin Chem 49, 1763-1773 (2003).

30. A. G. Beyene et al., Imaging striatal dopamine release using a nongenetically encoded near infrared fluorescent catecholamine nanosensor. Sci Adv 5, eaaw3108 (2019).

31. T. Patriarchi et al., Ultrafast neuronal imaging of dopamine dynamics with designed genetically encoded sensors. Science 360, eaat4422 (2018).

32. F. Sun et al., A genetically encoded fluorescent sensor enables rapid and specific detection of dopamine in flies, fish, and mice. Cell 174, 481-496 e419 (2018).

33. J. Feng et al., A genetically encoded fluorescent sensor for rapid and specific in vivo detection of norepinephrine. Neuron 102, 745-761 e748 (2019).

34. F. Sun et al., New and improved GRAB fluorescent sensors for monitoring dopaminergic activity in vivo. bioRxiv https://doi.org/10.1101/2020.03.28.013722 (2020).

35. Y. Zhao et al., An expanded palette of genetically encoded $\mathrm{Ca}^{2+}$ indicators. Science 333, 1888-1891 (2011).

36. Y. Shen, M. D. Wiens, R. E. Campbell, A photochromic and thermochromic fluorescent protein. RSC Adv. 4, 56762-56765 (2014).

37. J. A. Ihalainen, P. Riekkinen, Jr., M. G. Feenstra, Comparison of dopamine and noradrenaline release in mouse prefrontal cortex, striatum and hippocampus using microdialysis. Neurosci Lett 277, 7174 (1999).

38. P. Devoto, G. Flore, On the origin of cortical dopamine: Is it a co-transmitter in noradrenergic neurons? Current Neuropharmacology 4, 115-125 (2006).

39. A. V. Leopold, D. M. Shcherbakova, V. V. Verkhusha, Fluorescent biosensors for neurotransmission and neuromodulation: engineering and applications. Front. Cell. Neurosci. 13, 474 (2019).

40. L. Ravotto, L. Duffet, X. Zhou, B. Weber, T. Patriarchi, A bright and colorful future for g-protein coupled receptor sensors. Front. Cell. Neurosci. 14, 67 (2020).

41. C. K. Kim, A. Adhikari, K. Deisseroth, Integration of optogenetics with complementary methodologies in systems neuroscience. Nat Rev Neurosci 18, 222-235 (2017). 
431 42. M. Machacek et al., Coordination of Rho GTPase activities during cell protrusion. Nature 461, 99$432103(2009)$.

433 43. S. Mehta et al., Single-fluorophore biosensors for sensitive and multiplexed detection of signalling 434 activities. Nat Cell Biol 20, 1215-1225 (2018).

435 44. Y. Okubo et al., Visualization of $\mathrm{Ca}^{2+}$ filling mechanisms upon synaptic inputs in the endoplasmic 436 reticulum of cerebellar Purkinje cells. J Neurosci 35, 15837-15846 (2015).

437 45. M. Inoue et al., Rational engineering of XCaMPs, a multicolor GECI suite for in vivo imaging of 438 complex brain circuit dynamics. Cell 177, 1346-1360 e1324 (2019).

439 46. V. Villette et al., Ultrafast two-photon imaging of a high-gain voltage indicator in awake behaving $440 \quad$ mice. Cell 179, 1590-1608 e1523 (2019).

441 47. M. Jing et al., An optimized acetylcholine sensor for monitoring in vivo cholinergic activity. bioRxiv 442 https://doi.org/10.1101/861690 (2019).

443 48. J. Wan et al., A genetically encoded GRAB sensor for measuring serotonin dynamics in vivo. bioRxiv $444 \quad$ https://doi.org/10.1101/2020.02.24.962282 (2020). 


\section{$445 \quad$ Figure legends}

446 Fig. 1. Development of R-GenGAR-DA1.1, which showed a positive response to dopamine (DA). (A) 447 Strategy to develop R-GenGAR-DA1.0. Left panels show a schematic illustration of human DRD1 and 448 the red fluorescent protein 'cpmApple' insertion site. Right panels show screening flow chart. Linker 449 sequences connecting DRD1 and cpmApple were randomly mutated using saturation PCR. The plasmids 450 expressing each linker mutant were isolated, followed by the transfection into HeLa cells by lipofection. 451 Changes in fluorescence intensity following $10 \mu \mathrm{M}$ DA stimulation was monitored by live-cell imaging 452 of HeLa cells expressing each mutant. ICL, intracellular loop; SP, signal peptide (hemagglutinin 453 secretary sequence). (B) Summary of screening results. The normalized fluorescence changes $\left(\Delta \mathrm{F} / \mathrm{F}_{0}\right)$ of 454 the HeLa cells expressing each mutant in response to $10 \mu \mathrm{M}$ DA stimulation are shown. Each bar 455 represents the average of 1-3 independent experiments. We selected a mutant "R-GenGAR-DA1.1" that 456 showed a maximum response to $10 \mu \mathrm{M}$ DA stimulation. $(C)$ Representative images of HeLa cells 457 expressing DA1.1 stimulated with $10 \mu \mathrm{M}$ DA. The fluorescence change $\left(\Delta \mathrm{F} / \mathrm{F}_{0}\right)$ before and after DA 458 stimulation are shown in the pseudocolor intensity-modulated display mode. (D) Normalized 459 fluorescence change $\left(\Delta \mathrm{F} / \mathrm{F}_{0}\right)$ of DA1.1 in HeLa cells in panel $C$. DA $(10 \mu \mathrm{M})$ and SCH $23390(\mathrm{SCH}, 10$ $460 \mu \mathrm{M}$ ) were treated at the time points indicated by pink and blue bars, respectively (SI Appendix, Fig. S5A). 461 Mean $\Delta \mathrm{F} / \mathrm{F}_{0}$ values of 10 cells from 1 experiment are shown with SD (shaded area). (E) Dose-response 462 curves, with temperature equilibration, of DA (pink) and NE (green) in HeLa cells expressing DA1.1 (SI 463 Appendix, Fig. S4D). DA: $\max \Delta \mathrm{F} / \mathrm{F}_{0}=0.23 \pm 0.02 \%$ and $\mathrm{EC}_{50}=0.45 \pm 0.21 \mu \mathrm{M} ; \mathrm{NE}: \max \Delta \mathrm{F} / \mathrm{F}_{0}=0.17$ $464 \pm 0.03 \%$ and $\mathrm{EC}_{50}=5.68 \pm 1.19 \mu \mathrm{M}(\mathrm{DA}$ and $\mathrm{NE}, n=3$ experiments in both cases, 10 cells per 465 experiment). Experimental data (dots) were fitted with the Hill equation (lines). DA1.1 has 12.6-fold selectivity for DA over NE.

468 Fig. 2. Development of R-GenGAR-DA1.2, which showed a negative red fluorescence response to DA. 
a linker in DA1.1. (B) Representative images of HeLa cells expressing DA1.2 treated with $10 \mu \mathrm{M}$ DA,

followed by $10 \mu \mathrm{M}$ DRD1/5 antagonist $\mathrm{SCH} 23390$ (SCH). Images are shown in the pseudocolor intensity-modulated display mode. $(C)$ Normalized fluorescence change $\left(\Delta \mathrm{F} / \mathrm{F}_{0}\right)$ of DA1.2 in HeLa cells.

Medium temperature was equilibrated before imaging (SI Appendix, Fig. S5B). DA (10 $\mu \mathrm{M})$ and SCH cells from 3 experiment are shown with SD (shaded area). Vehicle, $10 \mu \mathrm{M} \mathrm{HCl}$ or water; control, cells were only exposed to emission light. $(D)$ The dose-response curves, with temperature equilibration, of

DA (pink) and NE (green) on HeLa cells expressing DA1.2 (SI Appendix, Fig. S4D). DA: $\max \Delta \mathrm{F} / \mathrm{F}_{0}=$ $-0.40 \pm 0.01 \%$ and $\mathrm{EC}_{50}=0.68 \pm 0.08 \mu \mathrm{M} ; \mathrm{NE}: \max \Delta \mathrm{F} / \mathrm{F}_{0}=-0.45 \pm 0.05 \%$ and $\mathrm{EC}_{50}=98 \pm 51 \mu \mathrm{M}$

(DA and NE, $n=4$ experiments in both cases). Experimental data (dots) were fitted with the Hill equation

(lines). DA1.2 has 143-fold selectivity for DA over NE. (E) Selectivity of DA1.2 for pharmacological

compunds ( $n=3-4$ experiments, 10 cells per experiment; SI Appendix, Fig. S5C). All compounds were

serotonin (5-HT), glutamate (Glu), $\gamma$-aminobutyric acid (GABA), histamine (His), and acetylcholine

(ACh). For the vehicle condition, there was no significant difference between $10 \mu \mathrm{M} \mathrm{HCl} \mathrm{in} \mathrm{H}_{2} \mathrm{O}$ and

$0.001 \%$ dimethyl sulphoxide (DMSO) $(n=4$ experiments in each, 10 cells per experiment; Mann-

Whitney $U$-test, $P=0.69$ ). Therefore, these values were averaged and used as the vehicle condition.

Mean $\Delta \mathrm{F} / \mathrm{F}_{0}$ values are shown with SEM. One-way ANOVA, $F_{12,38}=53.11, P<0.0001$; Dunnett's post

hoc test (vs vehicle), $* * * * P<0.0001$.

Fig. 3. Dual-color fluorescence time-lapse imaging of R-GenGAR-DA1.2 combined with GRABNE1m in HeLa cells. $(A)$ Representative image of HeLa cells co-expressing DA1.2 and NE1m. $(B)$ Enlarged time-lapse images in the pseudocolor intensity-modulated display mode from the white boxed regions shown in panel $A$. Bars show the schedule of agonist/antagonist application to both DA1.2 and NE1m. 
Medium temperature and photochromism were equilibrated before imaging (SI Appendix, Fig. S5D). (C)

Normalized fluorescence intensity change $\left(\Delta \mathrm{F} / \mathrm{F}_{0}\right)$ of DA1.2 (top) and NE1m (bottom) in HeLa cells coexpressing DA1.2 and NE1m. Vehicle, $10 \mu \mathrm{M} \mathrm{HCl}$ in $\mathrm{H}_{2} \mathrm{O}$ or $0.001 \%$ DMSO; control, cells were only exposed to emission light. Mean $\Delta \mathrm{F} / \mathrm{F}_{0}$ values of 30 cells from 3 experiments are shown with $\mathrm{SD}$ (shaded areas). Result of statistical test is shown in SI Appendix, Fig. S9 $A$ and $B$.

Fig. 4. Characterization of R-GenGAR-DA1.2 in the primary culture of rat hippocampal neurons. $(A)$ $\left(\Delta \mathrm{F} / \mathrm{F}_{0}\right)$ before (left) and after the application of $5 \mu \mathrm{M}$ DA (middle) followed by $5 \mu \mathrm{M} \mathrm{SCH}$ (right) (SI Appendix, Fig. S5B) are shown in pseudocolor intensity-modulated display mode. Bottom: magnification of dendrite marked in the top left image (white rectangle). Medium temperature was equilibrated before imaging. $(B)$ Normalized fluorescence change $\left(\Delta \mathrm{F} / \mathrm{F}_{0}\right)$ of DA1.2 in the primary hippocampal neurons in panel $A$. DA $(5 \mu \mathrm{M})$ and SCH $(5 \mu \mathrm{M})$ were treated at the time points indicated by pink and blue bars, respectively. Mean $\Delta \mathrm{F} / \mathrm{F}_{0}$ values of 6 neurons from 6 experiments are shown with $\mathrm{SD}$ (shaded area). (C) DA1.2 was pre-treated with SCH before application of DA. Mean $\Delta \mathrm{F} / \mathrm{F}_{0}$ of 3 neurons from 3 experiments are shown with SD (shaded area). Medium temperature was equilibrated before imaging. $(D)$ The doseresponse curve with temperature equilibration of DA (pink) on the primary hippocampal neurons expressing DA1.2 (SI Appendix, Fig. S4D). DA: $\max \Delta \mathrm{F} / \mathrm{F}_{0}=-0.51 \pm 0.05 \%$ and $\mathrm{EC}_{50}=0.56 \pm 0.01$ $\mu \mathrm{M} ; n=7$ neurons from 7 experiments. Experimental data (dots) were fitted with the Hill equation (lines).

Fig. 5. R-GenGAR-DA1.2 combined with GRAB ${ }_{N E 1 m}$ enables dual-color fluorescence imaging of DA and NE in a primary culture of rat hippocampal neurons. $(A)$ Representative image of a primary 518 NE1m treated with agonists or antagonists in pseudocolor intensity-modulated display mode from the dendritic region in the primary hippocampal neurons marked as the white boxes in panel $A$. 
520 Concentrations: DA and SCH, $5 \mu \mathrm{M}$; NE and YO, $1 \mu \mathrm{M}$. Medium temperature and photochromism were

521 equilibrated before imaging (SI Appendix, Fig. S5D). (C) Normalized fluorescence intensity change $522\left(\Delta \mathrm{F} / \mathrm{F}_{0}\right)$ of DA1.2 (top) and NE1m (bottom) in the primary hippocampal neurons co-expressing DA1.2 523 and NE1m. Bars show the schedule of agonist/antagonist application to both DA1.2 and NE1m. Gray 524 vertical lines indicate time of application. Vehicle, $10 \mu \mathrm{M} \mathrm{HCl} \mathrm{in} \mathrm{H}_{2} \mathrm{O}$ or $0.001 \% \mathrm{DMSO}$; control, cells 525 were only exposed to emission light. Colored lines indicate mean $\Delta \mathrm{F} / \mathrm{F}_{0}$ and light-colored shaded area is 526 the SD. Ligands, 6 neurons from 6 experiments; vehicles, 4 neurons from 4 experiments; control, 4 527 neurons from 1 experiment. Statistical test results are shown in SI Appendix, Fig. S9 C and $D$. 


\section{Supplementary Information}

\section{A genetically encoded red fluorescence dopamine biosensor enables dual imaging of} dopamine and norepinephrine

Chihiro Nakamoto, Yuhei Goto, Yoko Tomizawa, Yuko Fukata, Masaki Fukata, Kasper Harpsøe, David

E. Gloriam, Kazuhiro Aoki, and Tomonori Takeuchi

\section{Materials and Methods}

Animals

Pregnant Wistar/ST rats were purchased from Japan SLC, Inc. for the primary cultures of rat hippocampal neurons. All experiments were approved by the Animal Care Committee of the National Institutes of Natural Sciences in Japan (19A029), and were performed in accordance with its guidelines. stock, 14332, CAY,), and L-adrenaline (epinephrine) (5 mM stock, A0173, TCI) were dissolved in 10 mM HCl. L-noradrenaline bitartrate monohydrate (1 M stock, A0906, TCI), sodium L-glutamate monohydrate (10 mM stock, G0188, TCI), 4-aminobutyric acid (100 mM stock, A0282, TCI), histamine (100 mM stock, 18111-71, Nacalai Tesque), acetylcholine chloride (10 mM stock, A6625, SigmaAldrich), and R(+)-SCH 23390 hydrochloride (10 mM stock, D054, Sigma-Aldrich) were each dissolved separately in distilled water. SKF 81297 hydrobromide (10 mM stock, 1447, TOCRIS), haloperidol 
hydrochloride (20 mM stock, 0931, TOCRIS), and yohimbine hydrochloride (20 mM stock, 1127,

TOCRIS) were dissolved in DMSO. Compound solutions were then subdivided into aliquots and stored at $-20{ }^{\circ} \mathrm{C}$ until use. A working solution of $1 \mathrm{M} \mathrm{DA}$ was stored at $4{ }^{\circ} \mathrm{C}$ for 3 weeks prior to use.

\section{Plasmids}

R-GenGAR-DA1.0 cDNA and dLight1.1 (Patriarchi et al., 2018) cDNA were synthesized by FASMAC

Co. Ltd. into the vector plasmid pUCFa (FASMAC Co. Ltd.). We used a cpmApple module with linker sequences (LSS-LI-cpmApple-NH-DQL) from RGECO1, which was a kind gift from Dr. Takeharu Nagai (Zhao et al., 2011), for insertion into human DRD1. Sequences coding for hemagglutinin (HA) secretion motif and a FLAG epitope were placed at the 5' end of the construct as in dLight1.1 (Patriarchi et al., 2018) (Fig. 1A). EcoRI and NotI recognition sites were placed at the 5' and 3' end, respectively, for subcloning into the expression vector, pCAGGS (Niwa et al., 1991) with the ligation by Ligation High ver.2 (TOYOBO). Point mutations of R-GenGAR-DA1, and dLight1.2 and dLight1.3a (Patriarchi et al., 2018) were made using polymerase chain reaction (PCR) with the primers containing each

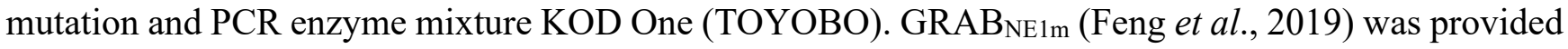
by Dr. Yulong Li and subcloned into the pCAGGS.

\section{Saturation PCR for the screening of optimal linker sequence}

To maximize the chromophore fluorescence changes according to the conformational change of R-

GenGAR-DA1.0, optimized linker sequences were screened by the saturated PCR. Primers with random bases encoding two-amino acid length were designed as follows. Forward Primer: 5'- 
DRD1-cpmApple plasmid with NEBuilder (NEB). This mutant library was transformed into E.coli and

the plasmid library was prepared from the mixture of transformed E.coli. Library plasmids were digested

by EcoRI and NotI to extract library insert. Library inserts were subcloned into the pCAGGS vector by

ligation and transformation into E.coli. Single E.coli colonies were picked up and the plasmids were

prepared from them. Each plasmid was transfected into HeLa cells seeded in 96-well glass-bottom plate

with 293-fectin (Thermo Fisher Scientific). Two days after the transfection, cells were imaged as

described below.

\section{Design of DRD1 mutations based on structural models}

Structural models of DRD1 with DA and NE were constructed using PyMOL (The PyMOL Molecular Graphics System, Version 2.0 Schrödinger, LLC) from a crystal structure of the related $\beta_{2}$-adrenoceptor with bound epinephrine (Ring et al., 2013) downloaded from the RCSB Protein Data Bank web site (http://www. pdb.org; PDB code, 4LDO). The binding site residues with side-chain atoms within $5 \AA$ of epinephrine's aliphatic hydroxy group was exchanged for those of DRD1 by selecting high-probability backbone-dependent rotamers suggested by the mutagenesis wizard in PyMOL. DA was built by deleting the additional methyl plus aliphatic hydroxy group and NE by deleting only the methyl group. Using the same cut-off as above, Ser 107, Val 317 and Trp 321 were identified as residues that could potentially interact with the extra hydroxy group on NE. Asp 103 was disregarded as it is essential for binding of both agonists by interacting with the protonated amine.

With the aim of lowering the binding affinity of NE by removing a potential hydrogen bond to the aliphatic hydroxy of NE, Ser 107 was mutated to Cys and Ala. Additionally, to introduce steric hinderance around the aliphatic hydroxy group, Ile, Leu, Met and Val mutations were also performed. Val 317 was mutated to other hydrophobic residues with longer side chains, that is, Ile, Leu, Phe and Met, again to introduce steric hinderance around the hydroxy in NE. Trp 321 was first mutated to Phe to remove the 
hydrogen bonding possibility whilst maintaining aromaticity, but since this was detrimental to DA and

NE binding, we attempted other residues that maintained hydrogen bonding possibility, that is, His and

Gln.

\section{Cell culture}

HeLa cells were purchased from the Human Science Research Resources Bank. HeLa cells were cultured in DMEM (Wako) supplemented with 10\% fetal bovine serum (Sigma-Aldrich) at $37{ }^{\circ} \mathrm{C}$ in $5 \% \mathrm{CO}_{2}$. HeLa cells $\left(3 \times 10^{4}\right.$ cells/well) were plated on CELLview cell culture dishes (glass bottom, $35 \mathrm{~mm}$ diameter, 4 compartments; The Greiner Bio-One) (SI Appendix, Fig. S4A) one day before transfection. Transfection was performed by incubating the cells with a mixture containing $250 \mathrm{ng}$ DNA and $0.25 \mu \mathrm{l}$ 293fectin transfection reagent (Thermo Fisher Scientific) per well for 4-6 h. Imaging was performed 2 days after transfection.

Primary cultures of rat hippocampal neurons were prepared similarly to that described previously (Fukata et al., 2013). Pregnant Wistar/ST rats were purchased from Japan SLC, Inc. A pregnant rat with embryonic rats (embryonic days 19) was killed by $\mathrm{CO}_{2}$ inhalation and then embryos (10 embryos per pregnant rat) were removed and decapitated. Hippocampi were dissected from embryonic rat brains and placed in a $10 \mathrm{~cm}$ dish on ice with a Hanks'-buffered saline $\left(\mathrm{Ca}^{2+} / \mathrm{Mg}^{2+}\right.$ free; CMF-HBSS $)$ containing: Hanks' Balanced Salt solution (Sigma-Aldrich), $10 \mathrm{mM}$ glucose, and $10 \mathrm{mM}$ Hepes (pH 7.4). To dissociate hippocampal neurons, hippocampi were treated with 10 units/ml papain (Worthington Biochemical) for $10 \mathrm{~min}$ at $37^{\circ} \mathrm{C}$. Dissociated neurons were plated onto poly-L-lysine (Sigma-Aldrich)coated $35 \mathrm{~mm}$-glass bottom dishes $\left(3 \times 10^{5}\right.$ cells/well $)($ SI Appendix, Fig. S4A) with a plating medium containing: neurobasal medium (ThermoFisher Scientific), 10\% FBS, and $10 \mathrm{mM}$ Hepes (pH 7.4). Neurons were incubated at $37^{\circ} \mathrm{C}$ and $5 \% \mathrm{CO}_{2}$ for $3 \mathrm{~h}$, and then the medium was replaced by a medium containing: neurobasal medium, B-27 supplement (ThermoFisher Scientific), 2 mM GlutaMax 
supplement-I (ThermoFisher Scientific), and $10 \mathrm{mM}$ Hepes (pH 7.4). Half of the medium was removed and replaced with fresh medium every 7 days. The cultured neurons were transfected at 14-21 days in vitro by Lipofectamine 2000 (Thermo Fisher Scientific) and were imaged 4-6 days after transfection.

\section{Fluorescence imaging}

For the imaging of HeLa cells, the medium was changed to imaging buffer [FluoroBrite D-MEM (FB), Life Technologies] supplemented with 1\% GlutaMAX (Life Technologies), and $0.2 \%$ fetal bovine serum at least $2 \mathrm{~h}$ before imaging. For primary hippocampal neurons, the medium was changed to HBSS [119 $\mathrm{mM} \mathrm{NaCl}, 5 \mathrm{mM} \mathrm{KCl}, 2 \mathrm{mM} \mathrm{CaCl}_{2}, 25 \mathrm{mM}$ Hepes (pH 7.4), $2 \mathrm{mM} \mathrm{MgCl}$, and $33 \mathrm{mM}$ D-glucose] before imaging started.

For the screening of optimal linkers, HeLa cells transfected with library plasmids were imaged with a high content imaging system, IXM-XLS (Molecular Device), equipped with an air objective lens (CFI Plan Fluor 10×, NA $=0.30, \mathrm{WD}=16 \mathrm{~mm}$ and CFI Plan Apochromat Lambda $20 \times, \mathrm{NA}=0.75$, $\mathrm{WD}=1 \mathrm{~mm}$; Nikon), a Zyla $5.5 \mathrm{sCMOS}$ camera (ANDOR) and a SOLA SE II light source (Lumencor). The excitation and fluorescence filter settings were as follows: excitation filter 562/40 (FF01-562/40-25), dichroic mirror 350-585/601-950 (T) (FF593-Di03-25×36), and emission fluorescence filter 624/40 (FF01-624/40-25) purchased from Semrock. Fluorescence changes before and after application of $10 \mu \mathrm{M}$ DA were imaged by the IXM-XLS (Molecular Device).

Confocal fluorescence imaging of cells were imaged with an IX83 inverted microscope (Olympus) equipped with a sCMOS camera (Prime, Photometrics), an air objective lens (UPLSAPO $20 \times$, NA $=$ $0.75, \mathrm{WD}=0.6 \mathrm{~mm}$ or UPLXAPO $20 \times, \mathrm{NA}=0.8, \mathrm{WD}=0.6 \mathrm{~mm}$; Olympus), an oil objective lens (UPLSAPO $60 \times, \mathrm{NA}=1.35, \mathrm{WD}=0.15 \mathrm{~mm}$ or $\mathrm{UPLXAPO} 60 \times, \mathrm{NA}=1.42, \mathrm{WD}=0.15 \mathrm{~mm}$; Olympus) and a spinning disk confocal unit (CSU-W1, Yokogawa Electric Corporation), illuminated with a laser merge module containing $440 \mathrm{~nm}, 488 \mathrm{~nm}$, and $561 \mathrm{~nm}$ lasers. The excitation laser and fluorescence filter 
settings were as follows: excitation laser, $440 \mathrm{~nm}$ [for cyan fluorecent protein (CFP) and fluorescence

resonance energy transfer (FRET) with cyclic adenosine monophosphate (cAMP) biosensor)], $488 \mathrm{~nm}$ (for NE1m) and $561 \mathrm{~nm}$ (for DA1.2); excitation dichroic mirror, DM445/514/640 (for cAMP biosensor; $500 \mathrm{~nm}$ (CFP for cAMP biosensor; Yokogawa Electric), 500-550 nm (for NE1m and FRET for cAMP biosensor; Yokogawa Electric), and 580-654 nm (for DA1.2; Yokogawa Electric).

\section{Compounds used to test fluorescence response}

Stock solutions for the compounds were dissolved in the appropriate vehicle and $0.95 \sim 1 \mu \mathrm{l}$ in each 1.5$\mathrm{ml}$ microcentrifuge tube was prepared. Compounds were mixed with $0.5 \mathrm{ml}$ imaging buffer from the well and applied to the same well at each time point during the imaging (SI Appendix, Fig. S4B). For temperature equilibration of the imaging buffer, $0.5 \mathrm{ml}$ of the imaging buffer was transferred from the well into an empty $1.5-\mathrm{ml}$ microcentrifuge tube and then applied to the buffer in the same well; the procedure repeated 5 times (SI Appendix, Fig. S4C). The procedure for the compound application in the time-lapse imaging is shown in SI Appendix, Fig. S5. The 'ligand' dissolved in the appropriate vehicle was applied at the imaging time point shown by the arrow; the 'vehicle' was applied at the same time point. The 'control' only had light exposure for evaluating the effects of photochromism.

\section{Detection of cAMP signaling using cAMP biosensor}

The cAMP biosensor 'CFP-Epac-YFP (yellow fluorescent protein)', which was developed based on previous work (Ponsioen et al., 2004), contains monomeric teal fluorescent protein (mTFP), the human RAPGEF3 (EPAC) gene (corresponding to 149-881 a.a.) obtained from HeLa cells with RT-PCR, and mVenus. The cDNA of cAMP biosensor was inserted into pCX4neo vector (Akagi et al., 2003). The plasmid was co-transfected with either DRD1-Tango, which was a gift from Dr. Bryan Roth (Addgene 
144 kit \# 1000000068) (Kroeze et al., 2015), DA1.2, or empty vector. The cells were imaged 2 days after

145 transfection. The level of cAMP was calculated by the ratio of CFP to FRET, followed with normalization

146 by the baseline value before DA application.

\section{Quantification of imaging and data analysis}

149 We used Fiji, a distribution of ImageJ (Schindelin et al., 2012), for the preparation of quantification and measurement of all imaging files. Principally, for all images, background was subtracted and images were registered by StackReg, a Fiji plugin to correct misregistration, if required. Note that the median filter was used for the time-lapse images of the neuron before registration to remove camera noise preventing registration. Then, regions of interests (ROIs) were selected for the first time point in timelapse imaging or in the images before the compound application, to surround the whole cell body for HeLa cells and a dendrite near the cell body for hippocampal neurons. Mean pixel intensity in ROIs were measured and these data were further analyzed by Python3 (https://www.python.org). In order to normalize the fluorescence changes with the amount of biosensor expression, $\Delta \mathrm{F} / \mathrm{F}_{0}$ was calculated with the intensity before the compound application as $F_{0}$. The fluorescence change $\left(\Delta F / F_{0}\right)$ image is represented as the pseudocolor intensity-modulated display mode, where color represents the relative ratio value, whilst the brightness of the color represents the fluorescence intensity of the source images. binding was expected.

\section{Statistical analysis}

166 All data were presented as mean, with error bars indicating \pm SEM if not otherwise specified. Statistical 167 analyses were performed using GraphPad Prism8 (GraphPad Software) and Python 3.0 (Python Software 
168 Foundation) with SciPy (SciPy.org) and scikit-posthocs (https://scikit-posthocs.readthedocs.io/)

169 packages. Data were analyzed using Mann-Whitney $U$-test; Student's $t$-test; one-way ANOVA followed

170 by Dunnett's or Tukey-Kramer's post hoc tests as appropriate to correct for multiple comparisons;

171 Friedman test followed by Conover-Iman test with the Bonferroni-Holm correction to correct for multiple

172 comparisons. In Fig. S3 $E$ and $F$, normality assumption was judged from Shapiro-Wilk test and Q-Q plot

173 and variances among conditions was supposed to be equal by Bartlett test. All statistical tests were two-

174 tailed. The level of significance was set $P<0.05$. 
Fig. S1. Screening of R-GenGAR-DA1.1. (A) Time-lapse imaging of R-GenGAR-DA1.0. Mean $\Delta \mathrm{F} / \mathrm{F}_{0}$ by the pink bar. $(B)$ Time-lapse imaging of DA1.0_310 and DA1.0_430. Mean $\Delta \mathrm{F} / \mathrm{F}_{0}$ of 10 cells are shown with SD (shaded area). DA $(10 \mu \mathrm{M})$ and SCH $23390(\mathrm{SCH}, 10 \mu \mathrm{M})$ were treated at the indicated time points shown by pink and blue bars, respectively. (C) The amino acid sequence of linker sequences for DA1.0, DA1.1 (DA1.0_76), DA1.0_310, and DA1.0_430, which were obtained from 1st screening.

Fig. S2. Characterization of R-GenGAR-DA1.1_F129A. (A) Schematic illustration of DA1.1_F129A. Phe 129, located in DRD1 intracellular loop 2, mutated to alanin (F129A). (B) Time-lapse imaging of DA1.1_F129A. DA $(10 \mu \mathrm{M})$ and $\mathrm{SCH}(10 \mu \mathrm{M})$ were treated at the indicated time points. Mean $\Delta \mathrm{F} / \mathrm{F}_{0}$ of 20 cells from 2 independent experiments are shown with SD (shaded area).

Fig. S3. Thermochromism and photochromism for R-GenGAR-DA. $(A-D)$ Representative images of HeLa cells expressing DA1.1 $(A)$, and DA1.2 $(C)$ shown in the pseudocolor intensity-modulated display mode in various incubation temperatures. Regression curve of normalized fluorescence intensity change $\left(\triangle \mathrm{F} / \mathrm{F}_{0}\right)$ of DA1.1 $(B)$, and DA1.2 $(D)$ and incubation temperature. Negative correlation between

193 fluorescent intensity and temperature in DA1.1 $(\mathrm{r}=-0.960,20$ cells in 2 experiments) and DA1.2 ( $\mathrm{r}=$ $194-0.927,30$ cells in 3 experiments) were observed by Pearson product moment correlation coefficient. $(E)$

195 Photochromism-induced change in fluorescence intensity of HeLa cells expressing DA1.2 under the indicated conditions (excitation light wavelength, excitation light power, and exposure time). Incubation temperature was constant during time-lapse imaging. Images were taken every $3 \mathrm{~s}$. The colored-lines represent the average values with the SD of them (shaded area) ( $n=10$ cells in each case). Differences 
amongst area under the curves (AUCs) from 4 exposure conditions were tested as follows. Normality assumption was judged from Shapiro-Wilk test and Q-Q plot. Variances among conditions was assumed equal following Bartlett test $(P=0.696)$. One-way ANOVA was performed $\left(F_{3,36}=110, P<0.01\right)$. As a post-hoc analysis, Tukey-Kramer was used for multiple comparisons $(* P<0.05, * * P<0.01)$. $(F)$ Repeated time-lapse imaging of DA1.2 in primary hippocampal neuron without application of any compounds. Light irradiation protocol as follows: 1-s exposure of $561 \mathrm{~nm}$ followed by 1-s exposure of $488 \mathrm{~nm}$; every $3 \mathrm{~s}$ for a duration of $150 \mathrm{~s}$. Mean $\Delta \mathrm{F} / \mathrm{F}_{0}$ values of first (blue) and second (orange) $150-\mathrm{s}$ imaging are shown the SD of them (shaded area) $\left(n=4\right.$ neurons). Although the mean $\Delta \mathrm{F} / \mathrm{F}_{0}$ values in first 150-s imaging increased gradually because of the photochromism, those in second 150-s imaging were relatively constant and stable. Difference between AUC of first and second imaging was tested by a two-tailed paired $t$-test $(P=0.007)$.

Fig. S4. Optimized experimental procedure for the dose-response curve. $(A)$ Dishes for imaging of HeLa cells and primary hippocampal neurons. (B) Application of compounds for imaging. The compounds, mixed with the $0.5 \mathrm{ml}$ imaging buffer from the well of interest, was applied at the time of imaging. $(C)$

214 Temperature equilibration for imaging. Imaging buffer $(0.5 \mathrm{ml}$ out of $1 \mathrm{ml}$ for HeLa cells, and $2 \mathrm{ml}$ for the neurons) from the well of interest transferred to the empty 1.5-ml microcentrifuge tube and returned to the same well; repeated five times. This procedure gradually equilibrated the temperature of the imaging buffer to room temperature and effected the basal fluorescence level of DA1.1 and DA1.2 stable. (D) Procedure for making the dose-response curve. Top: the time course of ligand application and imaging shown by the arrow after temperature equilibration. Application of the diluted ligand, imaged sequentially. Bottom: representative images of DA1.2, negatively responding to DA in a dose-dependent manner. (E) Quantification of snapshots in the HeLa cells expressing DA1.2 in the dose-response curve for DA without (left) or with (right) temperature equilibration. Temperature equilibration effected to 
stabilize the basal level $\Delta \mathrm{F} / \mathrm{F}_{0}$ values of DA1.2. (Left, $n=4$ cells; right, $n=3$ cells). $(F)$ Confirmation of

were treated with 7 trials of vehicle stimulation after temperatuire equilibration, showing no change in the mean $\Delta \mathrm{F} / \mathrm{F}_{0}$ values with the SEM of them ( $n=3$ experiments in each). The procedure is the same as SI Appendix, Fig. S4D.

Fig. S5. Time course of application of compounds for imaging in HeLa cells and primary hippocampal neurons. (A) Compound application for time-lapse imaging without temperature equilibration. Compound or vehicle applied with imaging buffer from the well of interest shown by the arrow. Cells were imaged with the appropriate time exposure (SI Appendix, Table S1) acquired every $3 \mathrm{~s}$ for a duration of 90 s. (B) Compound application with temperature equilibration for time-lapse imaging. Before compound application, temperature equilibration conducted as shown in SI Appendix, Fig. S4C. Cells were imaged with the appropriate time exposure (SI Appendix, Table S1) acquired every $3 \mathrm{~s}$ for a duration of 90 s. (C) Compound application for checking pharmacological selectivity of DA1.2. Cells were imaged with the appropriate time exposure (SI Appendix, Table S1) acquired every $3 \mathrm{~s}$ for a duration of $60 \mathrm{~s}$. Averaged $\Delta \mathrm{F} / \mathrm{F}_{0}$ during 30-60 s of each compound was shown in Fig. 2E. (D) Compound application for dual-color imaging. After temperature equilibration, we conducted dual-color light irradiation (1-s exposure of $561 \mathrm{~nm}$ followed by 1-s exposure of $488 \mathrm{~nm}$ light irradiation) every $3 \mathrm{~s}$ for a duration of 150 s, which reduced the effect of photochromism, before the start of the imaging. Cells were dual-color imaged (561 nm followed by $488 \mathrm{~nm}$ light irradiation) with the appropriate time exposure (SI Appendix, Table S1) acquired every $3 \mathrm{~s}$ for a duration of $150 \mathrm{~s}$.

Fig. S6. Introducing structural mutations into R-GenGAR-DA1.2. (A) Prediction of the residues responsible for the selectivity between DA and NE from structural models of the DRD1 (light blue 
cartoon and white sticks) with either DA (left, salmon sticks) or NE (right, green sticks) in the binding site. The amino acids close to the additional hydroxy of NE (i.e. Ser 107, Val 317 and Trp 321) may be utilized to affect the preference for binding of DA over NE, e.g. by mutation of hydrogen bonding (yellow dotted lines) amino acids with hydrophobic ones. (B) Candidates of structural mutation. (C) Mean $\Delta \mathrm{F} / \mathrm{F}_{0}$ (20 cells from 2 experiments in each case) are shown with the SD of them (shaded area). DA (10 $\mu \mathrm{M})$ and $\mathrm{SCH}(10 \mu \mathrm{M})$ were treated at the indicated time points shown by pink and blue bars, respectively.

(D) Averaged $\Delta \mathrm{F} / \mathrm{F}_{0}$ during DA application (30-s duration) of each mutant was shown as mean $\pm \mathrm{SEM}$.

(E) The dose-response curves with temperature equilibration of DA (pink) and NE (green) in HeLa cells expressing DA1.2_V317I, DA1.2_V317M, and DA1.2_W321H (SI Appendix, Fig. S4D). DA1.2_V317I:

$\mathrm{DA}: \max \Delta \mathrm{F} / \mathrm{F}_{0}=0.49 \pm 0.01 \%$ and $\mathrm{EC}_{50}=1.10 \pm 0.24 \mu \mathrm{M} ; \mathrm{NE}: \max \Delta \mathrm{F} / \mathrm{F}_{0}=0.47 \pm 0.03 \%$ and $\mathrm{EC}_{50}$

$=55 \pm 14 \mu \mathrm{M} ; 50$-fold selectivity for DA over NE (DA and NE, $n=3$ experiments in both cases).

DA1.2_V317M: DA: $\max \Delta \mathrm{F} / \mathrm{F}_{0}=0.43 \pm 0.02 \%$ and $\mathrm{EC}_{50}=0.66 \pm 0.11 \mu \mathrm{M} ; \mathrm{NE}: \max \Delta \mathrm{F} / \mathrm{F}_{0}=0.42 \pm$

in both cases). DA1.2_W321H: DA: $\max \Delta \mathrm{F} / \mathrm{F}_{0}=0.55 \pm 0.06 \%$ and $\mathrm{EC}_{50}=12.0 \pm 7.4 \mu \mathrm{M}$; NE: $\max$ $\Delta \mathrm{F} / \mathrm{F}_{0}=0.62 \pm 0.07 \%$ and $\mathrm{EC}_{50}=111 \pm 12 \mu \mathrm{M} ; 9.3$-fold selectivity for DA over NE (DA and NE, $n=3$ experiments in both cases). Experimental data (dots) were fitted with the Hill equation (lines).

Fig. S7. Comparison of selectivity for DA over NE between R-GenGAR-DA and dLight1 sensors. $(A)$ dLight1.3a. dLight1.1: DA: $\max \Delta \mathrm{F} / \mathrm{F}_{0}=0.95 \pm 0.054 \%$ and $\mathrm{EC}_{50}=0.71 \pm 0.083 \mu \mathrm{M} ; \mathrm{NE}: \max \Delta \mathrm{F} / \mathrm{F}_{0}=$ $0.78 \pm 0.11 \%$ and $\mathrm{EC}_{50}=12 \pm 0.55 \mu \mathrm{M}$ (DA and NE, $n=4$ independent experiments in both cases)

dLight1.2: DA: $\max \Delta \mathrm{F} / \mathrm{F}_{0}=4.2 \pm 0.19 \%$ and $\mathrm{EC}_{50}=2.3 \pm 0.32 \mu \mathrm{M} ; \mathrm{NE}: \max \Delta \mathrm{F} / \mathrm{F}_{0}=2.8 \pm 0.25 \%$ and 
(DA and NE, $n=4$ independent experiments in both cases). (B) Summarized affinity for DA and NE, and

selectivity for DA over NE of R-GenGAR-DA1.1, R-GenGAR-DA1.2, dLight1.1, dLigh1.2, and dLight1.3a. Selectivity was calculated using $\mathrm{EC}_{50}$ of NE relative to $\mathrm{EC}_{50}$ of DA.

Fig. S8. cAMP signaling in HeLa cells expressing R-GenGAR-DA1.2. (A) Schematic illustration of the cAMP biosensor, CFP-Epac-YFP. $(B)$ Representative images of DRD1 (left), DA1.2 (middle), and control (right, empty vector), which were co-expressing CFP-Epac-YFP, before (top) and after (bottom) application of DA shown in the pseudocolor intensity-modulated display mode. $(C)$ Time-lapse imaging of cAMP level (CFP/FRET) in HeLa cells expressing DRD1 (blue), DA1.2 (pink), and control (gray). DA $(1 \mu \mathrm{M})$ was treated at the time points shown by the pink bar. Cells were imaged with the appropriate time exposure (SI Appendix, Table S1) acquired every $1 \mathrm{~min}$ for a duration of $30 \mathrm{~min}$. Mean CFP/FRET of 20 cells in 2 experiments is shown with the SD of them (shaded area).

Fig. S9. Statistical analysis of dual-color imaging of DA1.2 and NE1m in HeLa cells and primary hippocampal neurons. $(A$ and $C$ ) Quantification of mean values of time-lapse imaging from Fig. $3(A)$ and Fig. $5(C)$. Each $\Delta \mathrm{F} / \mathrm{F}_{0}$ value for a given compound was normalized by the subtraction of averaged vehicle values along the time course. Bars represent mean $\pm \mathrm{SEM} \Delta \mathrm{F} / \mathrm{F}_{0}$ values for each consecutive step in the experiment. Each bar represents the mean of the final $15 \mathrm{~s}$ ( 5 time points) of each $30 \mathrm{~s}$ condition, which occurs immediately prior to the application of each successive compound. The order of bars from left to right reflects the time course. (HeLa cells $n=30$ cells, neuron $n=6$ cells). ( $B$ and $D$ ) Statistical results of SI Appendix Fig.S $9 A(B)$ and $9 C(D)$. There were significant differences between compounds analyzed by Friedman test in HeLa cells (DA1.2, $P<0.001$; NE1m, $P<0.001$ ) and in hippocampal primary neurons (DA1.2, $P<0.001$; NE1m, $P<0.001$ ). Conover-Iman test with the Bonferroni-Holm correction for multiple testing, as a post-hoc analysis, $P$ values are shown in the table. n.s., not significant. 
Table S1 Conditions for fluorescent imaging

\begin{tabular}{|c|c|c|c|c|c|}
\hline Figure & Sensor & Cell-type & Microscopy & Filters & $\begin{array}{l}\text { Exposure time: } \\
\text { laser power }\end{array}$ \\
\hline Fig. $1 B$ & DA1.0 & $\mathrm{HeLa}$ & $\begin{array}{l}\text { IXM-XLS } \\
\begin{aligned} 10 \times(\mathrm{NA}=0.30) \\
20 \times(\mathrm{NA}=0.75)\end{aligned}\end{array}$ & $\begin{array}{l}\text { Ex: 562/40 } \\
\text { Dichroic: } \\
\text { 350-585/601-950 (T) } \\
\text { Em: } 624 / 40\end{array}$ & $\begin{array}{l}1000 \mathrm{~ms} \\
\text { (Lumen cor } 100 / 255)\end{array}$ \\
\hline $\begin{array}{l}\text { Fig. } 1 D \\
\text { Fig. S1 } A \& B \\
\text { Fig. S2 } B\end{array}$ & $\begin{array}{l}\text { DA1.0 } \\
\text { DA1.1 }\end{array}$ & HeLa & $\begin{array}{l}\text { IX83 } \\
\begin{array}{l}20 \times(\mathrm{NA}=0.75) \\
20 \times(\mathrm{NA}=0.80)\end{array}\end{array}$ & $\begin{array}{l}\text { Ex: } 561 \mathrm{~nm} \\
\text { Dichroic: } \\
\text { DM405/488/561 } \\
\text { Em: } 580-654 \mathrm{~nm}\end{array}$ & $\begin{array}{l}500 \mathrm{~ms} \\
\text { (Lumen cor 100/255) }\end{array}$ \\
\hline $\begin{array}{l}\text { Fig. } 1 E \\
\text { Fig. } 2 B-E \\
\text { Fig. } \mathrm{S} 3 A-D \\
\text { Fig. } \mathrm{S} 4 D \\
\text { Fig. S } 6 C-E\end{array}$ & $\begin{array}{l}\text { DA1.1 } \\
\text { DA1.2 }\end{array}$ & $\mathrm{HeLa}$ & $\begin{array}{l}\text { IX83 with CSU-W1 } \\
\begin{array}{l}20 \times(\mathrm{NA}=0.75) \\
20 \times(\mathrm{NA}=0.80)\end{array}\end{array}$ & $\begin{array}{l}\text { Ex: } 561 \mathrm{~nm} \\
\text { Dichroic: } \\
\text { DM405/488/561 } \\
\text { Em: } 580-654 \mathrm{~nm}\end{array}$ & $200 \mathrm{~ms}$ (ND $100 \%)$ \\
\hline Fig. S3E & DA1.2 & $\mathrm{HeLa}$ & $\begin{array}{l}\text { IX83 with CSU-W1 } \\
20 \times(\mathrm{NA}=0.75) \\
20 \times(\mathrm{NA}=0.80)\end{array}$ & $\begin{array}{l}\text { Ex1: } 561 \mathrm{~nm} \\
\text { Ex2: } 488 \mathrm{~nm} \\
\text { Dichroic: } \\
\text { DM405/488/561 } \\
\text { Em1: } 580-654 \mathrm{~nm} \\
\text { Em2: } 500-550 \mathrm{~nm}\end{array}$ & $\begin{array}{l}\text { Ex1: } 1000 \mathrm{~ms}(\mathrm{ND} 100 \%) \\
\text { Ex1: } 1000 \mathrm{~ms}(\mathrm{ND} 50 \%) \\
\text { Ex1, Ex2: } 1000 \mathrm{~ms} \text { (ND } \\
\text { 100\%) } \\
\text { Ex1, Ex2: } 200 \mathrm{~ms} \text { (ND } \\
50 \%)\end{array}$ \\
\hline Fig. 3 & $\begin{array}{l}\text { DA1.2 } \\
\text { NE1m }\end{array}$ & $\mathrm{HeLa}$ & $\begin{array}{c}\text { IX83 with CSU-W1 } \\
20 \times(\mathrm{NA}=0.75) \\
20 \times(\mathrm{NA}=0.80)\end{array}$ & $\begin{array}{l}\text { Ex1: } 561 \mathrm{~nm} \\
\text { Ex2: } 488 \mathrm{~nm} \\
\text { Dichroic: } \\
\text { DM405/488/561 } \\
\text { Em1: } 580-654 \mathrm{~nm} \\
\text { Em2: } 500-550 \mathrm{~nm}\end{array}$ & $\begin{array}{l}\text { Ex1: } 200 \mathrm{~ms}(\mathrm{ND} 100 \%) \\
\text { Ex2: } 200 \mathrm{~ms}(\mathrm{ND} 100 \%)\end{array}$ \\
\hline Fig. 4 & DA1.2 & Neuron & $\begin{array}{l}\text { IX83 with CSU-W1 } \\
60 \times \text { Oil }(\mathrm{NA}=1.35) \\
60 \times \text { Oil }(\mathrm{NA}=1.42)\end{array}$ & $\begin{array}{l}\text { Ex: } 561 \mathrm{~nm} \\
\text { Dichroic: } \\
\text { DM405/488/561 } \\
\text { Em: } 580-654 \mathrm{~nm}\end{array}$ & $1000 \mathrm{~ms}(\mathrm{ND} 10 \%)$ \\
\hline $\begin{array}{l}\text { Fig. } 5 \\
\text { Fig. S3F }\end{array}$ & $\begin{array}{l}\text { DA1.2 } \\
\text { NE1m }\end{array}$ & Neuron & $\begin{array}{l}\text { IX83 with CSU-W1 } \\
60 \times \text { Oil }(\mathrm{NA}=1.35)\end{array}$ & $\begin{array}{l}\text { Ex1: } 561 \mathrm{~nm} \\
\text { Ex2: } 488 \mathrm{~nm}\end{array}$ & $\begin{array}{l}\text { Ex1: } 1000 \mathrm{~ms}(\mathrm{ND} 10 \%) \\
\text { Ex2: } 1000 \mathrm{~ms}(\mathrm{ND} 5 \%)\end{array}$ \\
\hline
\end{tabular}


bioRxiv preprint doi: https://doi.org/10.1101/2020.05.25.115162; this version posted May 26, 2020. The copyright holder for this preprint (which

was not certified by peer review) is the author/funder, who has granted bioRxiv a license to display the preprint in perpetuity. It is made available under aCC-BY-NC-ND 4.0 International license.

\begin{tabular}{|c|c|c|c|c|c|}
\hline & & & $60 \times$ Oil $(\mathrm{NA}=1.42)$ & $\begin{array}{l}\text { Dichroic: } \\
\text { DM405/488/561 } \\
\text { Em1: } 580-654 \mathrm{~nm} \\
\text { Em2: } 500-550 \mathrm{~nm}\end{array}$ & \\
\hline Fig. S7 & $\begin{array}{l}\text { dLigh } 1.1 \\
\text { dLight1.2 } \\
\text { dLight1.3a }\end{array}$ & $\mathrm{HeLa}$ & $\begin{array}{l}\text { IX83 } \\
20 \times(\mathrm{NA}=0.75)\end{array}$ & $\begin{array}{l}\text { Ex: } 488 \mathrm{~nm} \\
\text { Dichroic: } \\
\text { DM405/488/561 } \\
\text { Em: DM405/488/561 }\end{array}$ & $\begin{array}{l}500 \mathrm{msec} \\
\text { (Lumen cor 20/255) }\end{array}$ \\
\hline Fig. S8 & $\begin{array}{l}\text { CFP-Epac } \\
\text {-YFP }\end{array}$ & $\mathrm{HeLa}$ & $\begin{array}{l}\text { IX83 with CSU-W1 } \\
20 \times(\mathrm{NA}=0.75)\end{array}$ & $\begin{array}{l}\text { Ex: } 440 \mathrm{~nm} \\
\text { Dichroic: } \\
\text { DM445/514/640 } \\
\text { Em (CFP): } 465-500 \mathrm{~nm} \\
\text { Em (FRET): } 500-550 \mathrm{~nm}\end{array}$ & $\begin{array}{l}500 \mathrm{~ms} \text { (ND 25\%) for CFP } \\
500 \mathrm{~ms} \text { (ND 25\%) for } \\
\text { FRET }\end{array}$ \\
\hline
\end{tabular}




\section{References}

300 Akagi, T., Sasai, K., and Hanafusa, H. (2003). Refractory nature of normal human diploid fibroblasts with respect to oncogene-mediated transformation. Proc Natl Acad Sci U S A 100, 13567-13572.

Feng, J., Zhang, C., Lischinsky, J.E., Jing, M., Zhou, J., Wang, H., Zhang, Y., Dong, A., Wu, Z., Wu, H., et al. (2019). A genetically encoded fluorescent sensor for rapid and specific in vivo detection of norepinephrine. Neuron 102, 745-761 e748.

Fukata, Y., Dimitrov, A., Boncompain, G., Vielemeyer, O., Perez, F., and Fukata, M. (2013). Local palmitoylation cycles define activity-regulated postsynaptic subdomains. J Cell Biol 202, 145-161.

Kroeze, W.K., Sassano, M.F., Huang, X.P., Lansu, K., McCorvy, J.D., Giguere, P.M., Sciaky, N., and

310 Niwa, H., Yamamura, K., and Miyazaki, J. (1991). Efficient selection for high-expression transfectants with a novel eukaryotic vector. Gene 108, 193-199.

Patriarchi, T., Cho, J.R., Merten, K., Howe, M.W., Marley, A., Xiong, W.H., Folk, R.W., Broussard, G.J., 313 Liang, R., Jang, M.J., et al. (2018). Ultrafast neuronal imaging of dopamine dynamics with designed genetically encoded sensors. Science 360 , eaat 4422 .

Ponsioen, B., Zhao, J., Riedl, J., Zwartkruis, F., van der Krogt, G., Zaccolo, M., Moolenaar, W.H., Bos, J.L., and Jalink, K. (2004). Detecting cAMP-induced Epac activation by fluorescence resonance energy transfer: Epac as a novel cAMP indicator. EMBO Rep 5, 1176-1180. $575-579$. 
321 Schindelin, J., Arganda-Carreras, I., Frise, E., Kaynig, V., Longair, M., Pietzsch, T., Preibisch, S., Rueden,

322 C., Saalfeld, S., Schmid, B., et al. (2012). Fiji: an open-source platform for biological-image analysis.

323 Nat Methods 9, 676-682.

324 Zhao, Y., Araki, S., Wu, J., Teramoto, T., Chang, Y.F., Nakano, M., Abdelfattah, A.S., Fujiwara, M.,

325 Ishihara, T., Nagai, T., et al. (2011). An expanded palette of genetically encoded $\mathrm{Ca}^{2+}$ indicators. Science $326333,1888-1891$. 
bioRxiv preprint doi: https://doi.org/10.1101/2020.05.25.115162; this version posted May 26, 2020. The copyright holder for this preprint (which was not certified by peer review) is the author/funder, who has granted bioRxiv a license to display the preprint in perpetuity. It is made available under aCC-BY-NC-ND 4.0 International license.

Figure 1

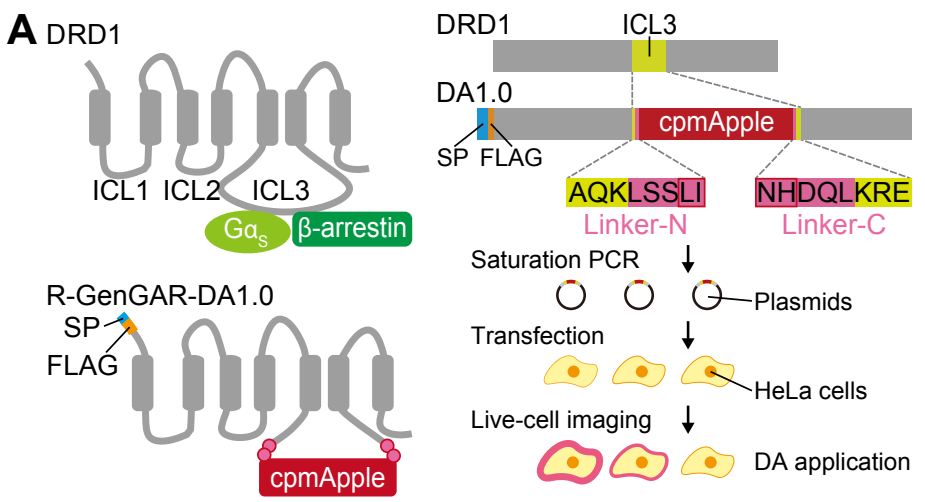

B
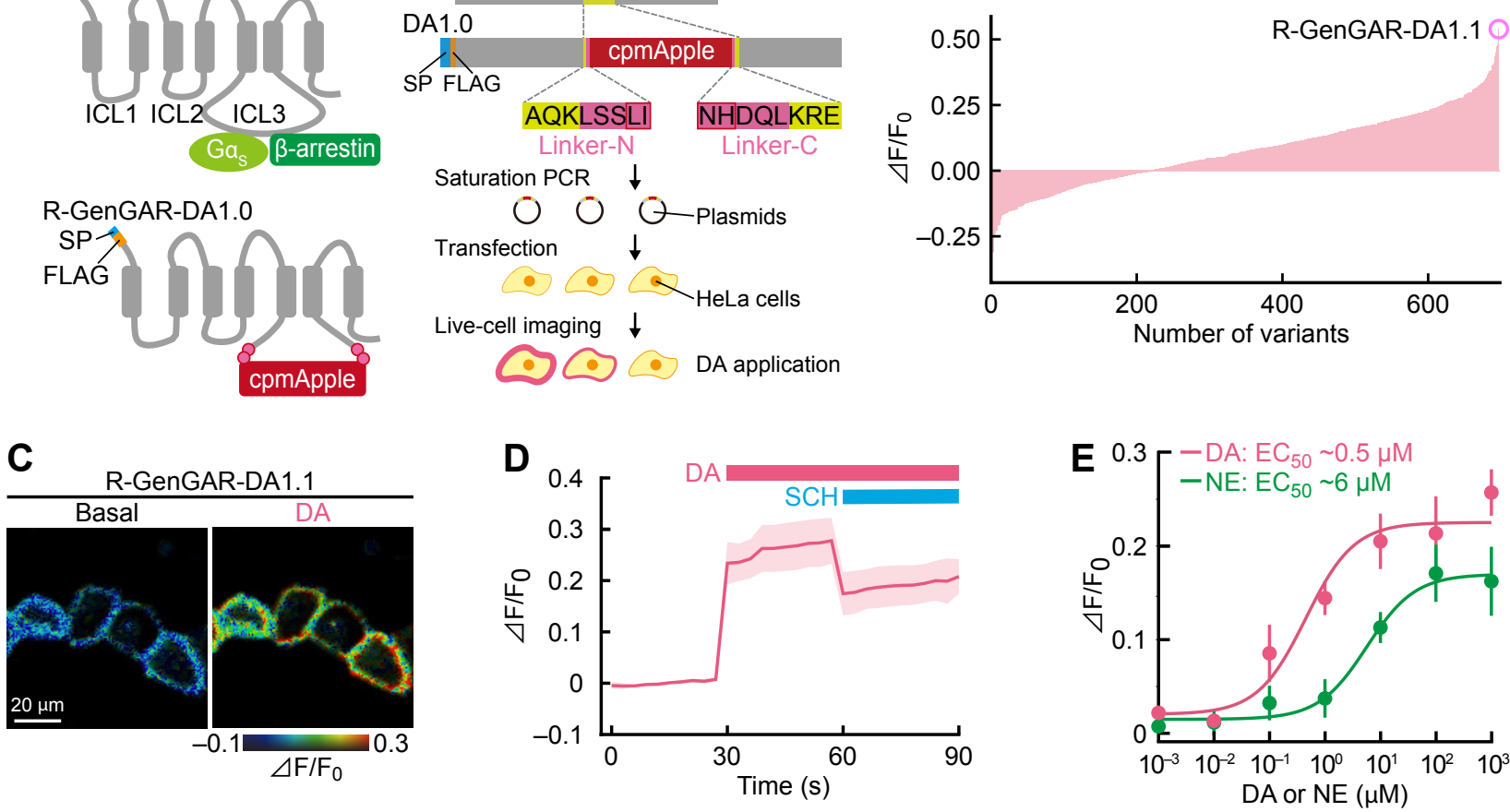
bioRxiv preprint doi: https://doi.org/10.1101/2020.05.25.115162; this version posted May 26, 2020. The copyright holder for this preprint (which was not certified by peer review) is the author/funder, who has granted bioRxiv a license to display the preprint in perpetuity. It is made available under aCC-BY-NC-ND 4.0 International license.

Figure 2

A

R-GenGAR-DA1.2

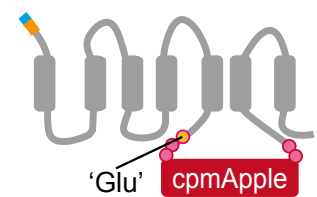

C

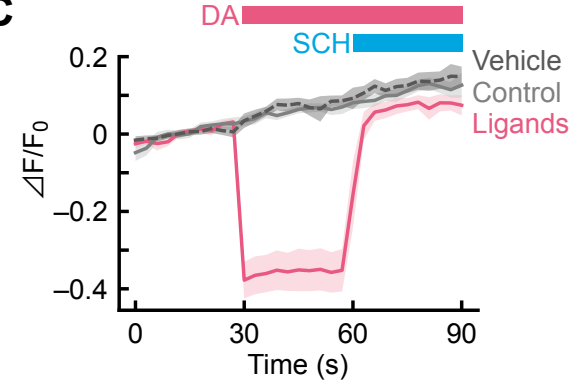

B

R-GenGAR-DA1.2
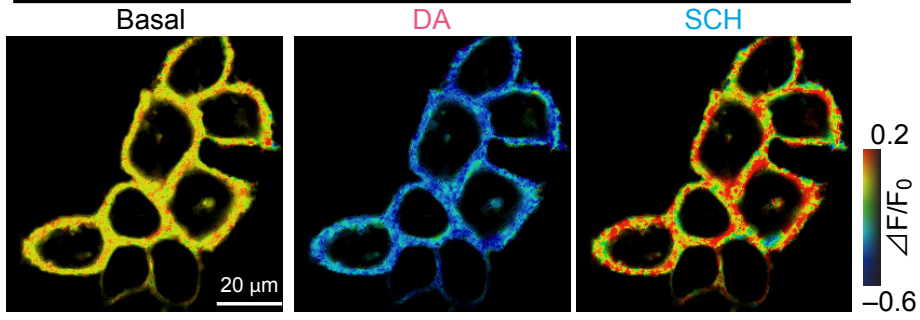

D

-DA: $\mathrm{EC}_{50} \sim 0.7 \mu \mathrm{M}$
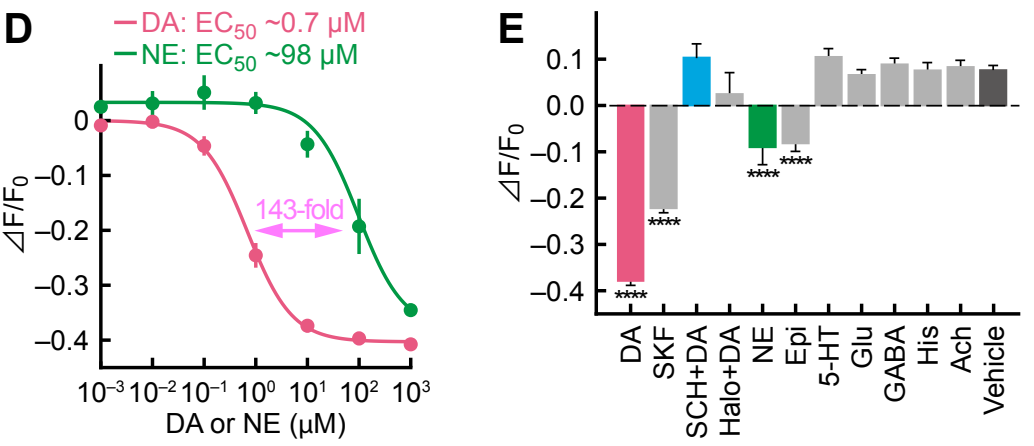
bioRxiv preprint doi: https://doi.org/10.1101/2020.05.25.115162; this version posted May 26, 2020. The copyright holder for this preprint (which was not certified by peer review) is the author/funder, who has granted bioRxiv a license to display the preprint in perpetuity. It is made available under aCC-BY-NC-ND 4.0 International license.

Figure 3

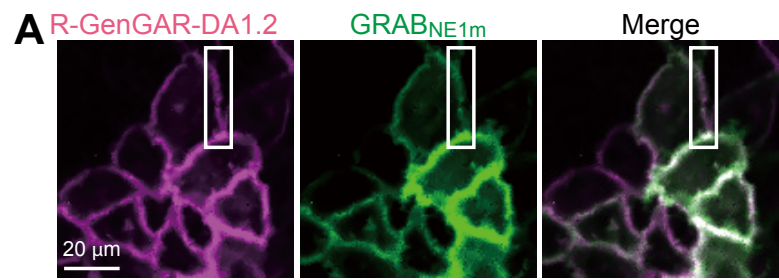

B

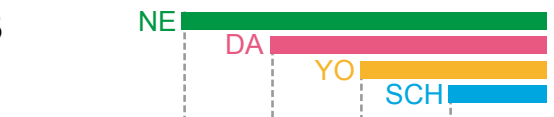

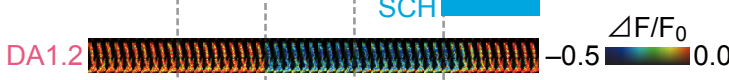

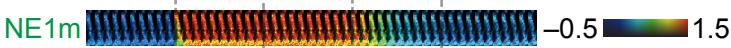
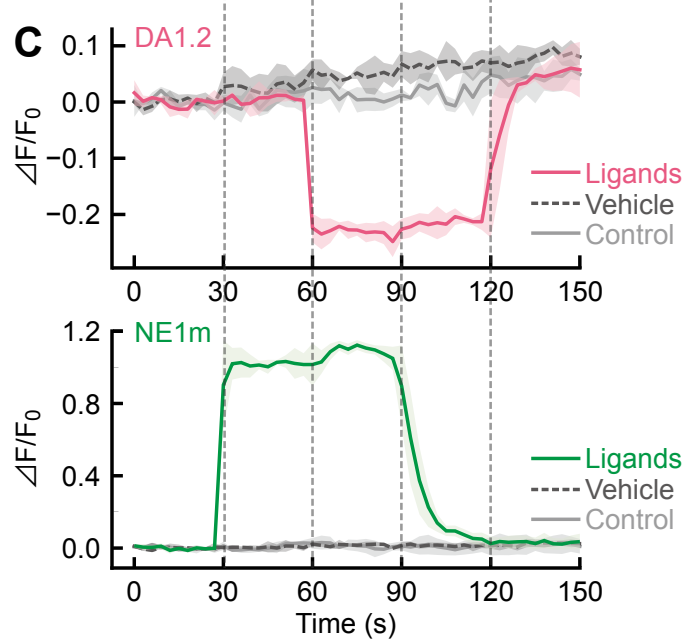
bioRxiv preprint doi: https://doi.org/10.1101/2020.05.25.115162; this version posted May 26, 2020. The copyright holder for this preprint (which was not certified by peer review) is the author/funder, who has granted bioRxiv a license to display the preprint in perpetuity. It is made available under aCC-BY-NC-ND 4.0 International license.

Figure 4

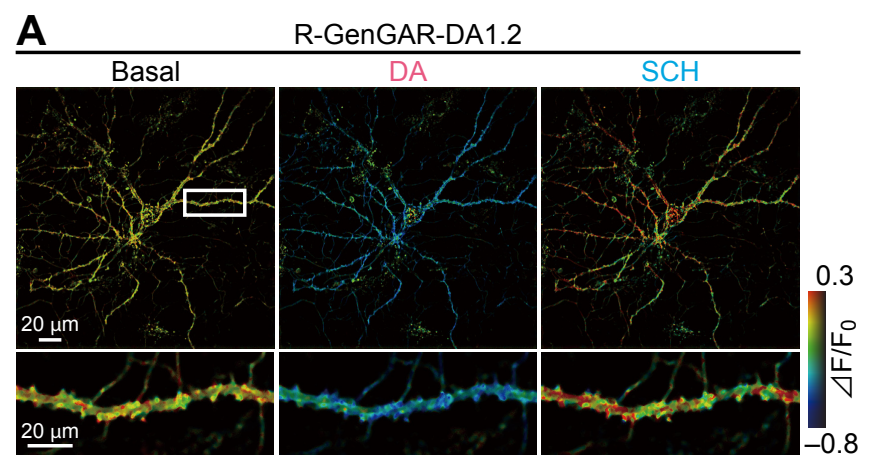

B

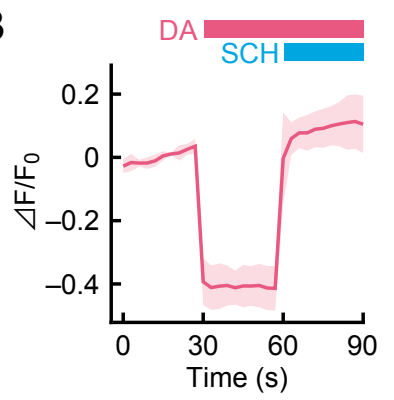

C

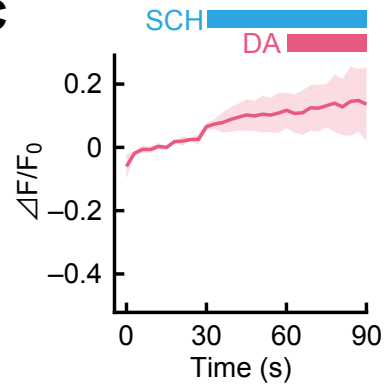

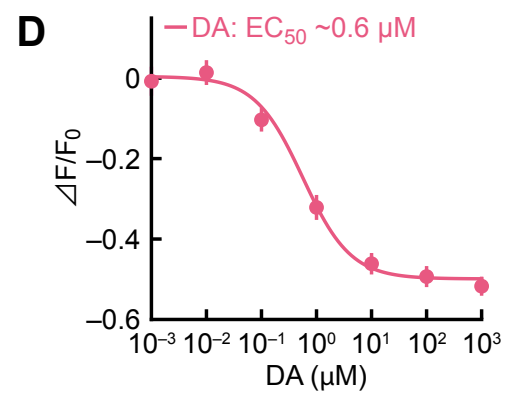


bioRxiv preprint doi: https://doi.org/10.1101/2020.05.25.115162; this version posted May 26, 2020. The copyright holder for this preprint (which was not certified by peer review) is the author/funder, who has granted bioRxiv a license to display the preprint in perpetuity. It is made available under aCC-BY-NC-ND 4.0 International license.

\section{Figure 5}

A

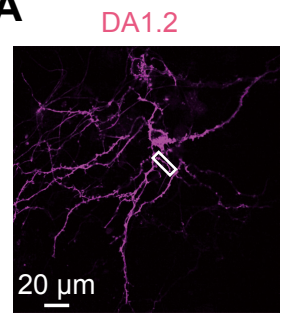

NE1m

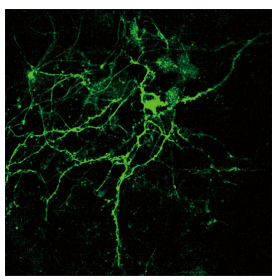

Merge

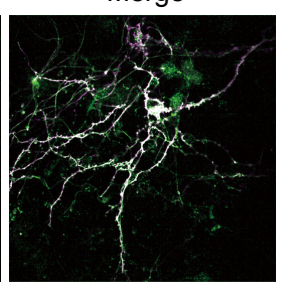

B

Basal NE

DA

DA1.2
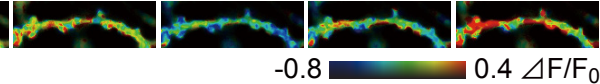

$\mathrm{NE} 1 \mathrm{~m}$ 5.Mm

$10+4$

C
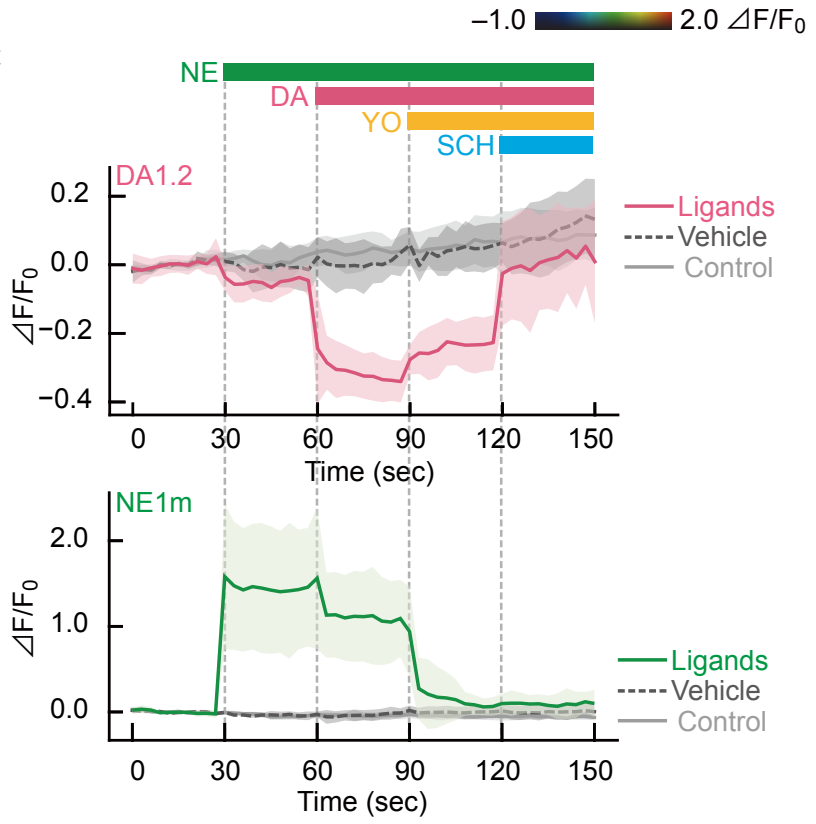
bioRxiv preprint doi: https://doi.org/10.1101/2020.05.25.115162; this version posted May 26, 2020. The copyright holder for this preprint (which was not certified by peer review) is the author/funder, who has granted bioRxiv a license to display the preprint in perpetuity. It is made available under aCC-BY-NC-ND 4.0 International license.

\section{Figure S1}

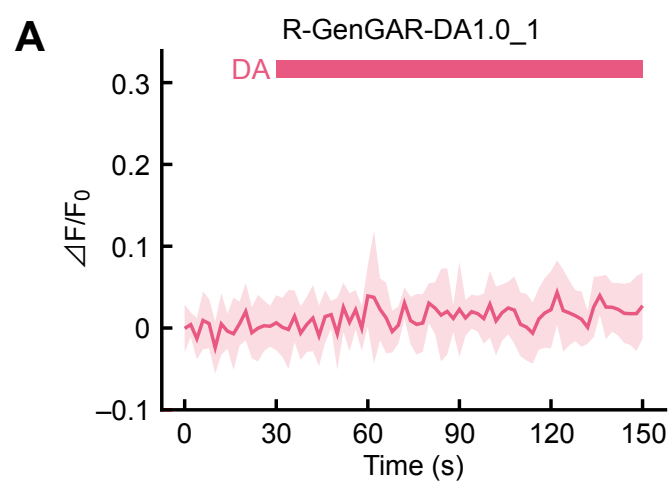

B

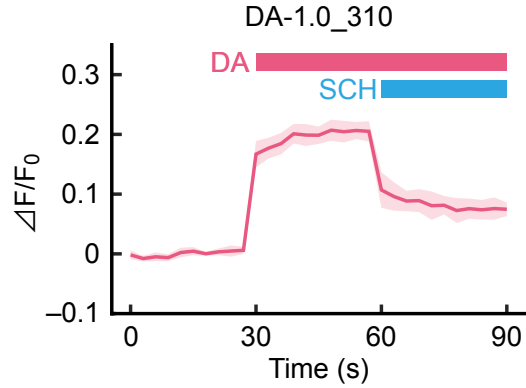

DA-1.0_430

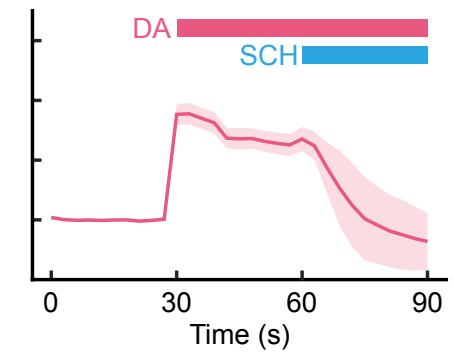

C $\mathrm{N}$-term side

C-term side

DA1.0 AGT AGT CTG ATC

AAT CAC GAT CAG

$\begin{array}{llll}S & \mathrm{~S} & \mathrm{I}\end{array}$

$\begin{array}{llll}\mathrm{N} & \mathrm{H} & \mathrm{D} & \mathrm{Q}\end{array}$

DA1.1 AGT AGT CCT GTG

CCC AGA GAT CAG

$\begin{array}{lllll}S & S & P & V\end{array}$

$\begin{array}{llll}\mathrm{P} & \mathrm{D} & \mathrm{Q}\end{array}$

DA1.0_310 AGT AGT GGT GTT TAC CCC GAT CAG

$\begin{array}{llll}S & \mathrm{~S} & \mathrm{G}\end{array}$

T P D $Q$

DA1.0 430 AGT AGT GGG ATT AGG CCC GAT CAG

S S G I $\begin{array}{llll}\mathrm{R} & \mathrm{P} & \mathrm{D} & \mathrm{Q}\end{array}$ 
bioRxiv preprint doi: https://doi.org/10.1101/2020.05.25.115162; this version posted May 26, 2020. The copyright holder for this preprint (which was not certified by peer review) is the author/funder, who has granted bioRxiv a license to display the preprint in perpetuity. It is made available under aCC-BY-NC-ND 4.0 International license.

Figure S2

A

R-GenGAR-DA1.1_F129A

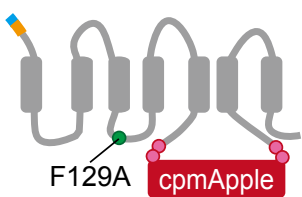

B

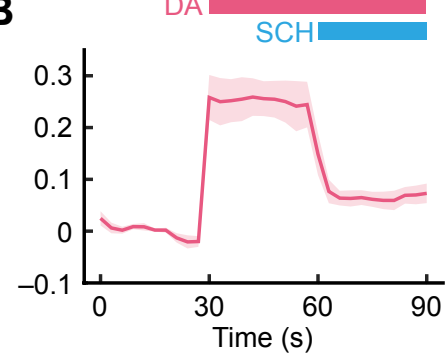


bioRxiv preprint doi: https://doi.org/10.1101/2020.05.25.115162; this version posted May 26, 2020. The copyright holder for this preprint (which was not certified by peer review) is the author/funder, who has granted bioRxiv a license to display the preprint in perpetuity. It is made available under aCC-BY-NC-ND 4.0 International license.

\section{Figure S3}

A R-GenGAR-DA1.1
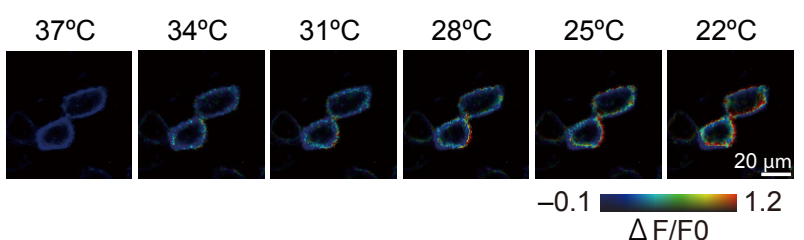

B

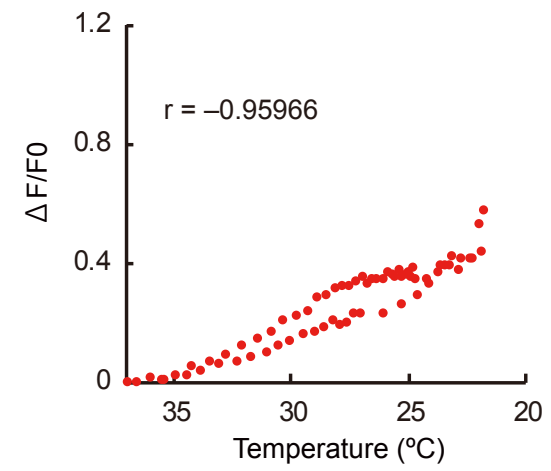

E

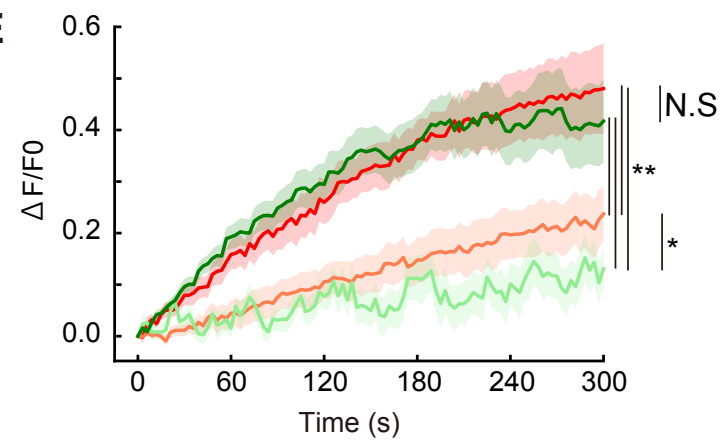

$561 \mathrm{~nm}, 100 \%, 1000 \mathrm{~ms}$

$561 \mathrm{~nm}, 50 \%, 1000 \mathrm{~ms}$

$488 \mathrm{~nm}$ and $561 \mathrm{~nm}, 100 \%, 1000 \mathrm{~ms}$

$488 \mathrm{~nm}$ and $561 \mathrm{~nm}, 50 \%, 200 \mathrm{~ms}$
C R-GenGAR-DA1.2
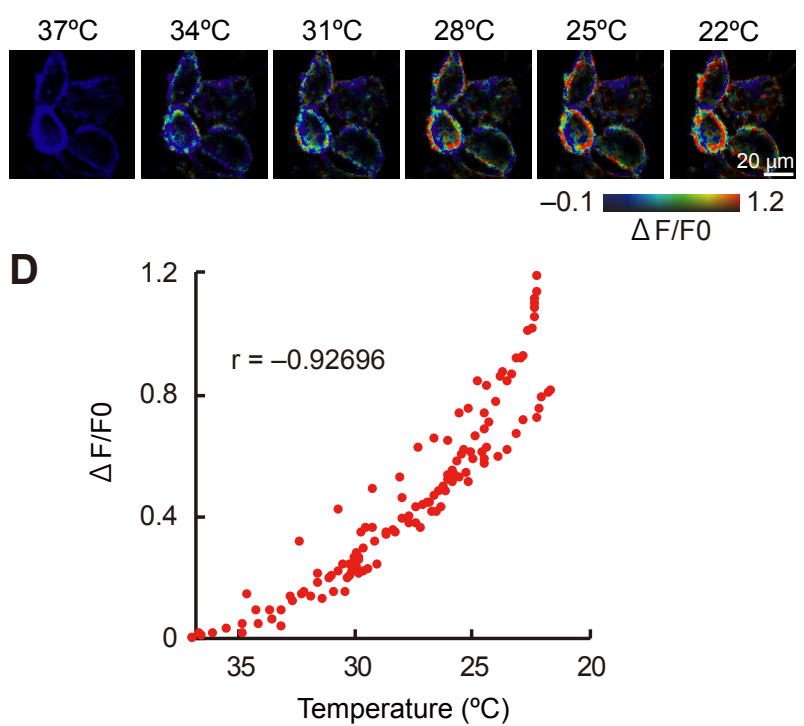

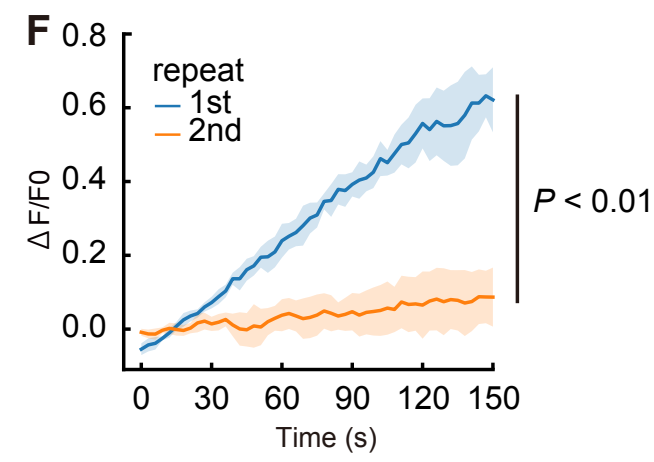


bioRxiv preprint doi: https://doi.org/10.1101/2020.05.25.115162; this version posted May 26, 2020. The copyright holder for this preprint (which was not certified by peer review) is the author/funder, who has granted bioRxiv a license to display the preprint in perpetuity. It is made available under aCC-BY-NC-ND 4.0 International license.

Figure S4

\section{A Dish for Imaging}

HeLa cells

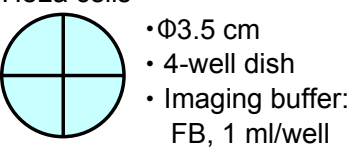

Neurons

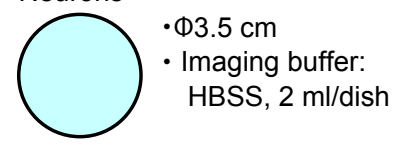

B Compound application for snapshot imaging

$\begin{gathered}\text { Prepared } \\ \text { compound or vehicle } \\ (0.95 \sim 1 \mu \mathrm{l})\end{gathered}$
$\begin{gathered}\text { Compound } \\ \text { or vehicle }\end{gathered}$

C Updated compound application for snapshot imaging

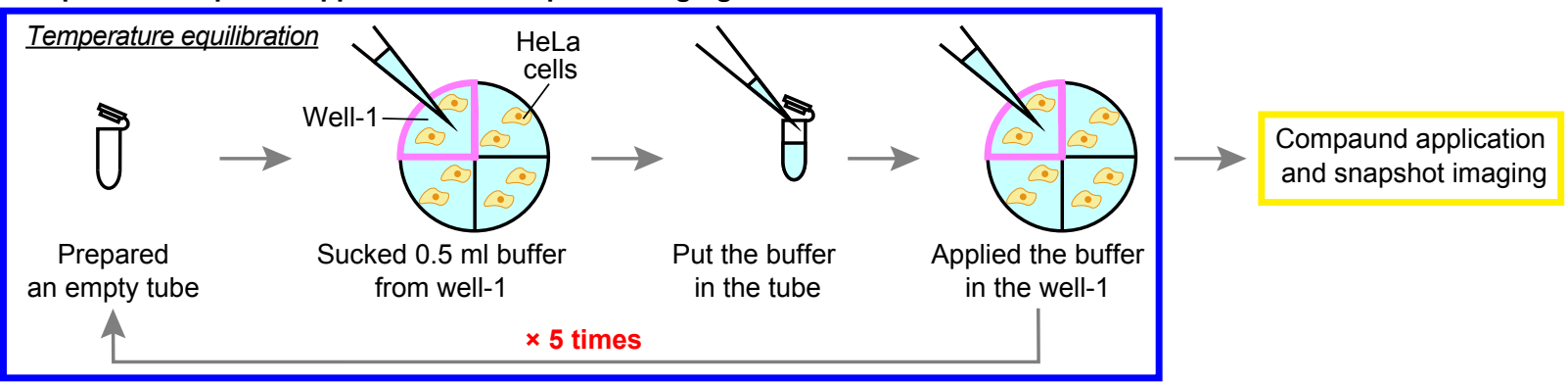

D Temperature equilibration followed by snap-shot imaging for dose-response curve

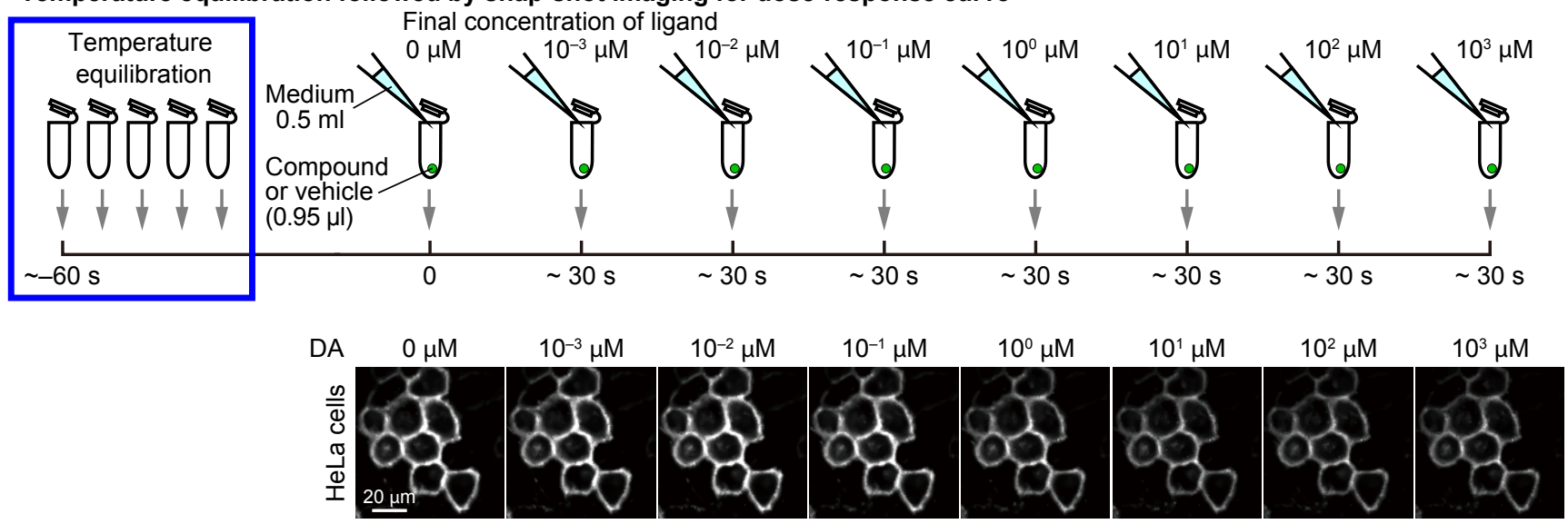

E Dose-response curve for DA Without temperature equilibration
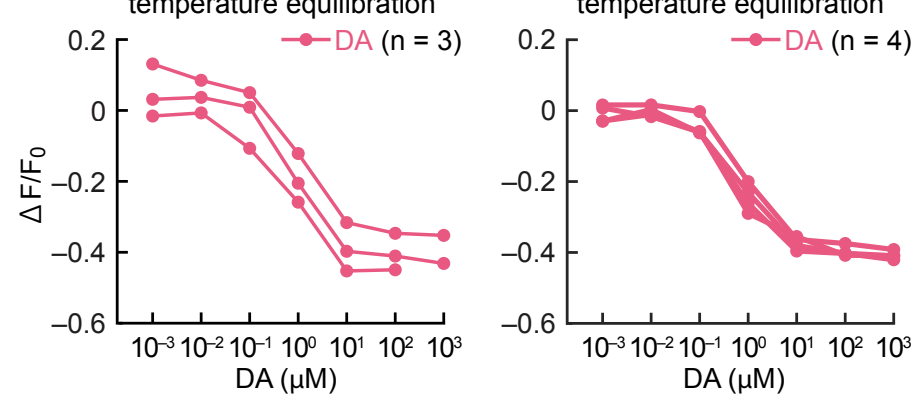

F Confirmation of R-GenGAR-DA1 stability
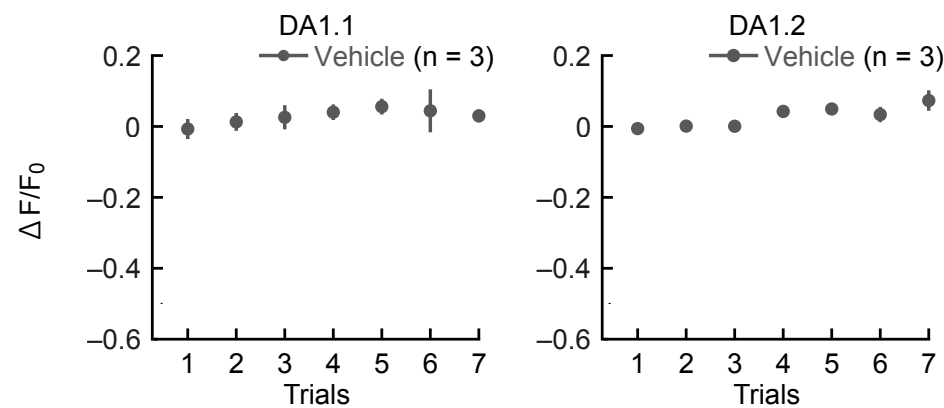
bioRxiv preprint doi: https://doi.org/10.1101/2020.05.25.115162; this version posted May 26, 2020. The copyright holder for this preprint (which was not certified by peer review) is the author/funder, who has granted bioRxiv a license to display the preprint in perpetuity. It is made available under aCC-BY-NC-ND 4.0 International license.

\section{Figure S5}

A Time-lapse imaging for response to DA (Fig. 1D, Fig. S1B and C, Fig. S2B, and Fig. S6C)

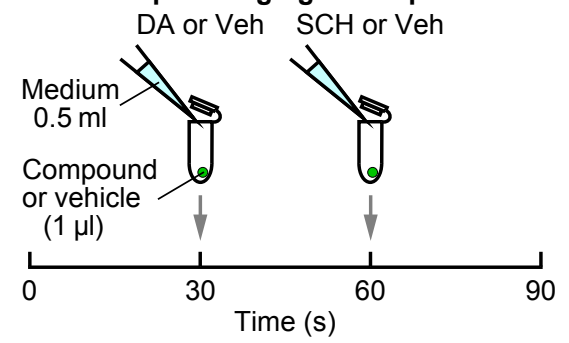

B Time-lapse imaging for response to DA with temperature equilibration (Fig. 2C, and Fig. 4B)

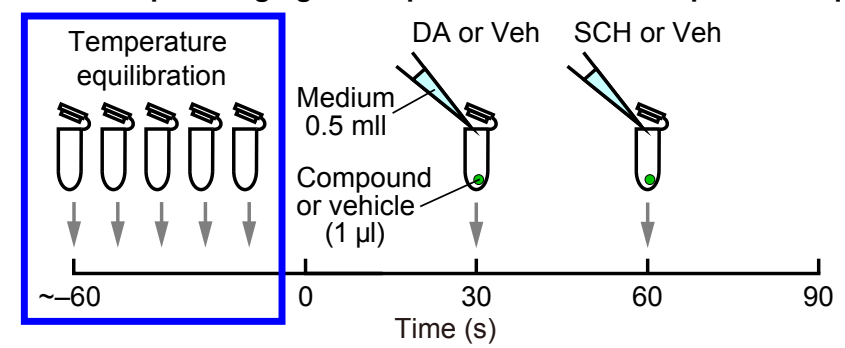

C Time-lapse imaging for ligand specificity (Fig. 2E)

Compound or Veh

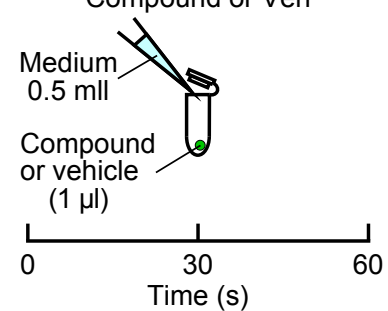

D Time-lapse imaging for dual-color imaging (Fig. 3, and Fig. 5)

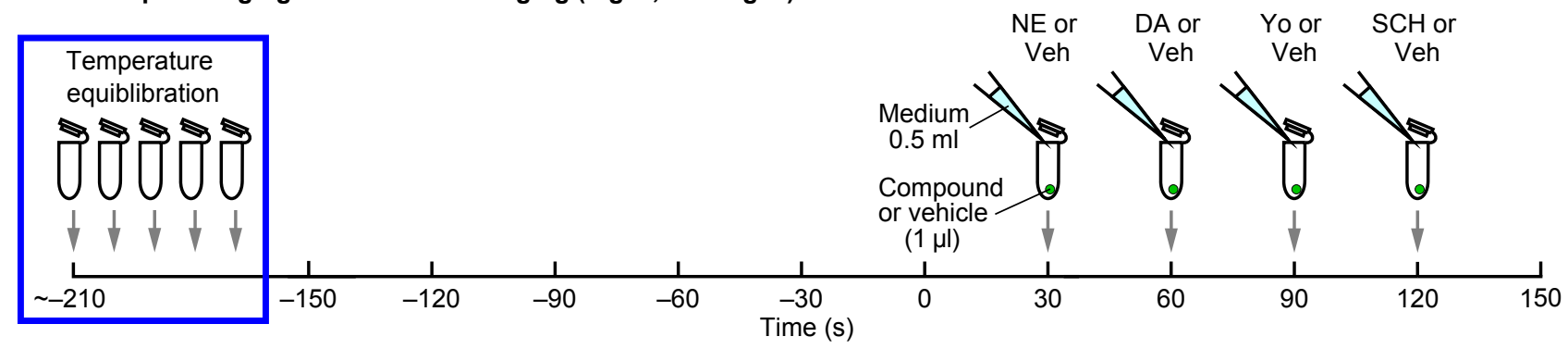


Fridgure, $\mathbf{S G}_{\text {(wich }}$ bioRxiv preprint doi: https://doi.org/10.1101/2020.05.25.115162; this version posted May 26, 2020. The copyrighthold

A

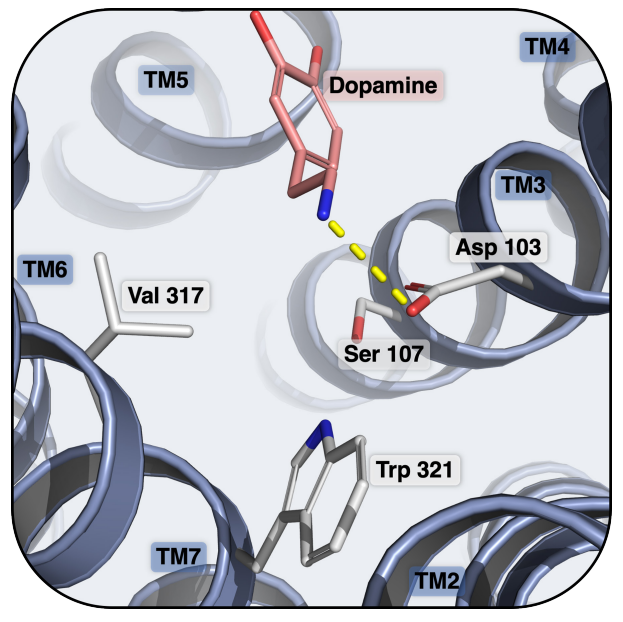
available under aCC-BY-NC-ND 4.0 International license.

B

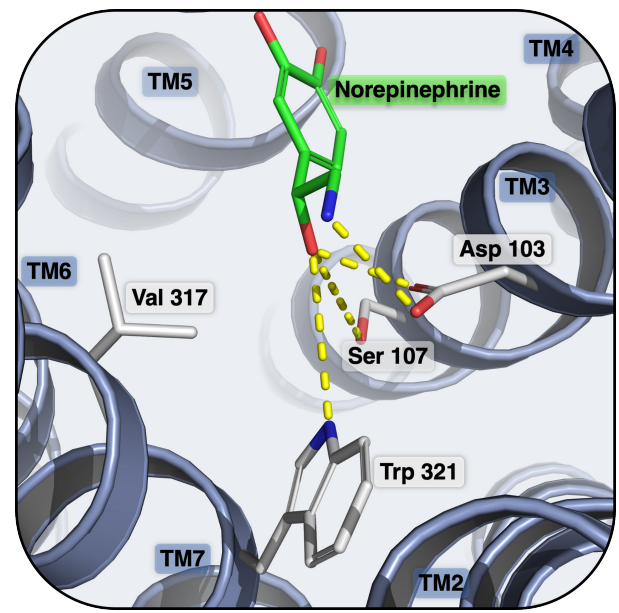

\begin{tabular}{ccc}
$\begin{array}{c}\text { S107 } \\
\text { (Ser 107) }\end{array}$ & $\begin{array}{c}\text { V317 } \\
\text { (Val 317) }\end{array}$ & $\begin{array}{c}\text { W321 } \\
\text { (Trp 321) }\end{array}$ \\
\hline S107A & V317F & W321F \\
S107C & V317I & W321H \\
S107I & V317L & W321Q \\
S107L & V317M & \\
S107M & & \\
S107V & & \\
\hline
\end{tabular}
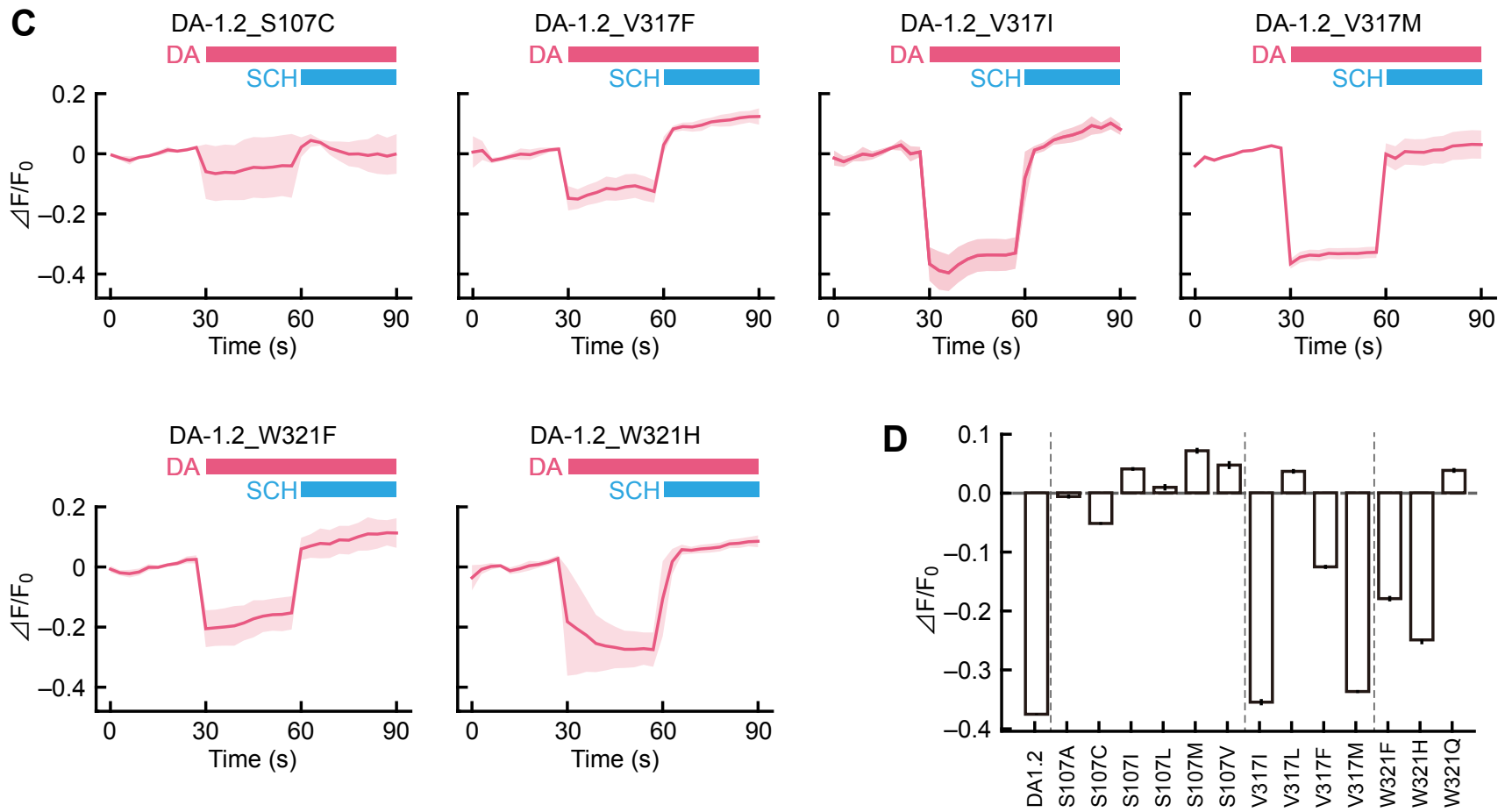

E
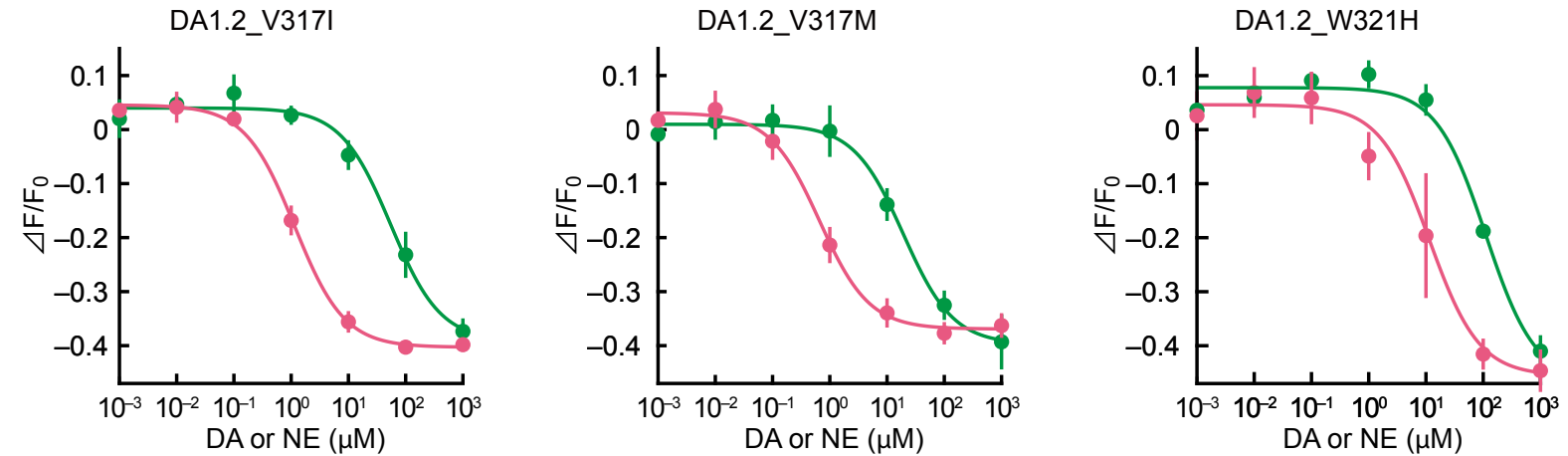
bioRxiv preprint doi: https://doi.org/10.1101/2020.05.25.115162; this version posted May 26, 2020. The copyright holder for this preprint (which was not certified by peer review) is the author/funder, who has granted bioRxiv a license to display the preprint in perpetuity. It is made available under aCC-BY-NC-ND 4.0 International license.

Figure S7

A
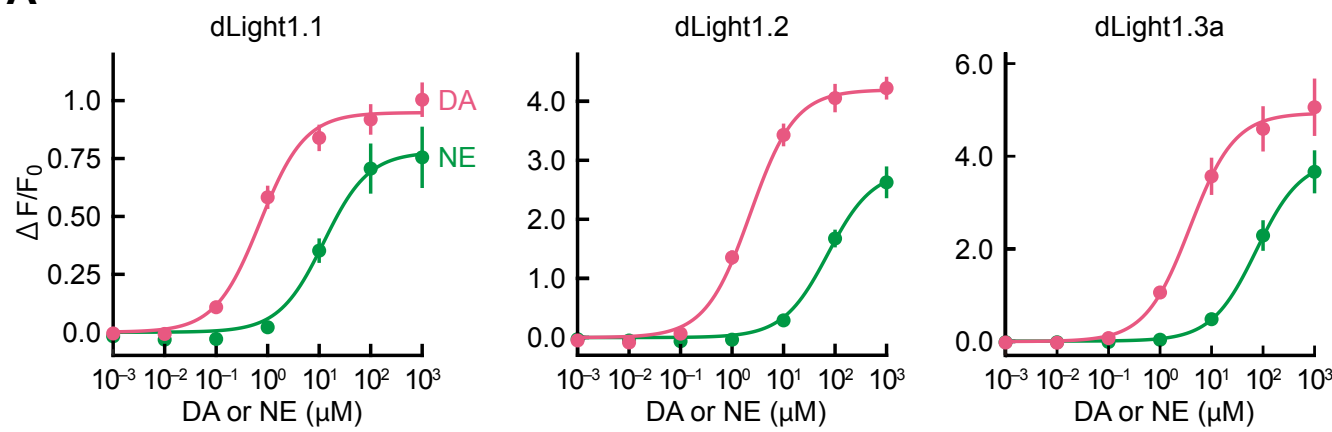

B

\begin{tabular}{lccc}
\hline DA biosensors & $\mathrm{DA}$ & $\mathrm{NE}$ & Specificity for \\
& $\mathrm{EC}_{50}(\mu \mathrm{M})$ & $\mathrm{EC}_{50}(\mu \mathrm{M})$ & $\mathrm{DA}$ over NE \\
\hline R-GenGAR-DA1.1 & 0.64 & 2.6 & 4-fold \\
R-GenGAR-DA1.2 & 0.68 & 97 & 143-fold \\
dLight1.1 & 0.71 & 12 & 17 -fold \\
dLight1.2 & 2.3 & 73 & 32-fold \\
dLight1.3a & 3.8 & 74 & 19-fold \\
\hline
\end{tabular}


bioRxiv preprint doi: https://doi.org/10.1101/2020.05.25.115162; this version posted May 26, 2020. The copyright holder for this preprint (which was not certified by peer review) is the author/funder, who has granted bioRxiv a license to display the preprint in perpetuity. It is made available under aCC-BY-NC-ND 4.0 International license.

\section{Figure S8}

A cAMP biosensor (Epac1)

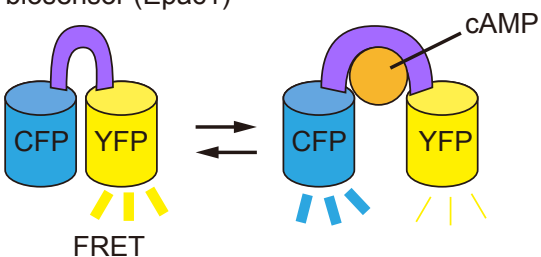

B

DRD1 DA1.2 Control
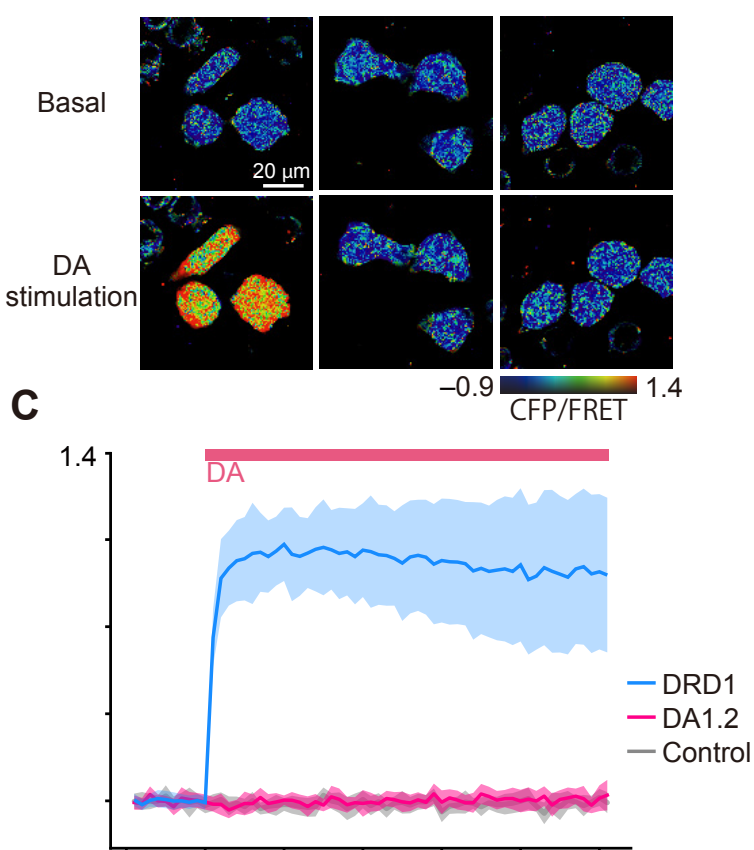
bioRxiv preprint doi: https://doi.org/10.1101/2020.05.25.115162; this version posted May 26, 2020. The copyright holder for this preprint (which was not certified by peer review) is the author/funder, who has granted bioRxiv a license to display the preprint in perpetuity. It is made available under aCC-BY-NC-ND 4.0 International license.

\section{Figure S9}

A HeLa
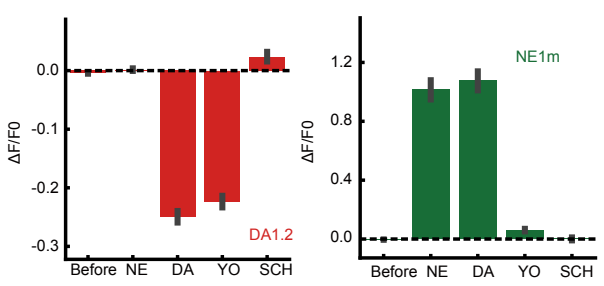

B HeLa

\begin{tabular}{|l|l|l|}
\hline & \multicolumn{1}{|c|}{ DA1.2 } & \multicolumn{1}{|c|}{ NE1m } \\
\hline Before-NE & n.s. & $P<0.001$ \\
Before-DA & $P<0.001$ & $P<0.001$ \\
Before-YO & $P<0.001$ & $P<0.001$ \\
\hline Before-SCH & $P<0.001$ & $P<0.01$ \\
NE-DA & $P<0.001$ & n.s. \\
NE-YO & $P<0.001$ & $P<0.001$ \\
NE-SCH & $P<0.05$ & $P<0.001$ \\
DA-YO & n.s. & $P<0.001$ \\
DA-SCH & $P<0.001$ & $P<0.001$ \\
YO-SCH & $P<0.001$ & $P<0.001$ \\
\hline
\end{tabular}

C Neuron
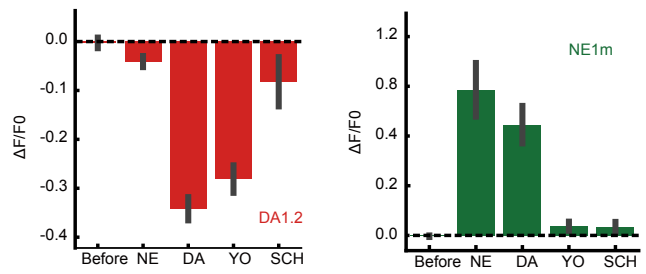

D Neuron

\begin{tabular}{|l|l|l|}
\hline & \multicolumn{1}{|c|}{ DA1.2 } & \multicolumn{1}{c|}{ NE1m } \\
\hline Before-NE & n.s. & $P<0.001$ \\
Before-DA & $P<0.001$ & $P<0.001$ \\
Before-YO & $P<0.001$ & n.s. \\
Before-SCH & n.s. & n.s. \\
NE-DA & $P<0.001$ & n.s. \\
NE-YO & $P<0.001$ & $P<0.001$ \\
NE-SCH & n.s. & $P<0.001$ \\
DA-YO & n.s. & $P<0.001$ \\
DA-SCH & $P<0.001$ & $P<0.001$ \\
YO-SCH & $P<0.001$ & n.s. \\
\hline
\end{tabular}

